\title{
8
}

\section{PERÚ: ENTRE LA CRISIS Y LA ESPERANZA ${ }^{1}$}

DOI: https://doi.org/10.7764/obitel.21.S.10

\begin{abstract}
Autores:
Giuliana Cassano² https://orcid.org/0000-0002-2686-5008, Guillermo Vásquez Fermi ${ }^{3}$ https://orcid.org/0000-0001-6115-3172, James A. Dettleff4 https://orcid.org/0000-0002-3603-1699

Equipo:

Thalia Dancuart, Renzo Miranda, Brunella Bertocchi, Mary Bustinza, María Isabel Ato, Lissi Torres, Kimberli López,

Priscilla Castro, Daniella Huamán, Andrea Soplin, César Moncayo, Rodrigo Nava
\end{abstract}

\section{Introducción}

Frente a la llegada de los primeros casos de Covid-19 al Perú, el gobierno del presidente Vizcarra decretó el confinamiento estricto el 16 de marzo de 2020, el cual duró -con etapas de flexibilización- hasta el 1 de julio. Esto generó una serie de cambios en la vida de los peruanos, y afectó las actividades de la producción televisiva. Sin posibilidades de producir ficción durante meses, los proyectos se paralizaron o cancelaron -incluyendo ficciones que estaban siendo emitidas- y los diferentes canales volcaron su programación hacia lo informativo, ampliando los

1 Agradecemos el apoyo de Kantar Ibope Media, que amablemente nos provee de los datos de audiencia utilizados en esta investigación.

2 Profesora Asociada de la Pontificia Universidad Católica del Perú.

3 Profesor Asociado de la Pontificia Universidad Católica del Perú.

4 Profesor Principal de la Pontificia Universidad Católica del Perú. 
horarios de los noticieros, los enlaces en vivo, y transmitiendo en cadena las conferencias de prensa del presidente. La pandemia sin embargo no logró estabilizar la crisis política que vive el país desde el 2016, y algunos canales de televisión se sumaron a las tentativas de un grupo de congresistas de hacerse con el poder.

Desde el Congreso -donde el presidente no tenía representación política- se generaron iniciativas populistas que crearon inestabilidad y enfrentamientos con el Ejecutivo. El Congreso acusó al presidente de corrupción, y logró su vacancia el 10 de noviembre por "permanente incapacidad moral", un término amplio e indefinido, sobre el cual el Tribunal Constitucional se negó a manifestarse por un vacío legal, a pesar de los pedidos de diversos políticos y del propio presidente. Con los intentos de vacancia al presidente Kuczynski (año 2018) y luego Vizcarra (año 2020), quedó demostrado que los motivos no son importantes, sino contar con los votos suficientes en el Congreso. Declarada la vacancia del presidente Vizcarra, ocupó su cargo el presidente del Congreso Manuel Merino. La población observó esto como un golpe de Estado de los grupos corruptos del Congreso, y a pesar del estado de emergencia sanitaria se dieron manifestaciones multitudinarias en todo el país, las de mayor asistencia en toda la historia del Perú. Luego de varios días de enfrentamientos de la población con la policía -que resultó en tres muertos y casi dos centenares de heridos- Merino renunció a la Presidencia el 15 de noviembre. Durante los pocos días que Merino fue presidente, el grupo de ciberactivismo Anonymous bloqueó diversas páginas web del Estado Peruano, así como la del canal de televisión Willax (promotor de la vacancia de Vizcarra), y la cuenta de Twitter de América Televisión. Este grupo ciberactivista, junto con un colectivo de k-popers, también lograron desactivar la cuenta del periodista Beto Ortiz, quien se burló de las marchas y sus víctimas.

Es en este contexto que la ficción televisiva tuvo que buscar nuevas formas para continuar al aire, intentando diferentes retornos a 
la producción, enfrentando nuevas cancelaciones, buscando adaptarse a la situación sanitaria, lo que finalmente trajo una reducción el número de episodios producidos en el año a la mitad de lo que se produjo hace siete años. La situación de la producción televisiva se fue normalizando hacia final del 2020, y la pantalla televisiva retornó a una programación similar a la de años previos.

En febrero de 2021, se anunció la muerte del peruano José Enrique Crousillat, productor de exitosas novelas en Venezuela, Argentina y luego en coproducción con Telemundo. Crousillat fue dueño de América Televisión y fundador de América Producciones, que relanzó la internacionalización de las novelas peruanas en los años 90. Tras la caída del régimen Fujimori-Montesinos, Crousillat huyó del país al descubrirse sus actos de corrupción. Una vez capturado fue condenado a ocho años de prisión.

\section{El Contexto Audiovisual de Perú en $\mathbf{2 0 2 0}$}

\section{La televisión abierta en Perú}

Cuadro 1. Cadenas/canales nacionales de televisión abierta en Perú

\begin{tabular}{|l|l|}
\hline \multicolumn{1}{|c|}{ Cadenas/canales privados (5) } & Cadenas/canales públicos (1) \\
\hline Latina (Canal 2) & TV Perú (Canal 7) \\
\hline América Televisión (Canal 4) & \\
\hline Panamericana Televisión (Canal 5) & \\
\hline ATV (Canal 9) & \\
\hline Global (Canal 13) TOTAL CADENAS $=\mathbf{6}$ \\
TOTAL CANALES $=\mathbf{6}$ \\
\hline
\end{tabular}

Fuente: Observatorio Audiovisual Peruano 
Gráfico 1. Rating y share de TV por emisora

\begin{tabular}{|l|c|c|c|}
\hline Emisora & Audiencia Hogares & Audiencia (\%) & Share (\%) \\
\hline América Televisión & 7,16 & 35,6 & 20,1 \\
\hline Latina & 4,55 & 22,6 & 12,8 \\
\hline ATV & 3,77 & 18,7 & 10,6 \\
\hline Panamericana Televisión & 1,79 & 8,9 & 5,0 \\
\hline Global & 1,79 & 8,9 & 3,0 \\
\hline TV Perú & 1,07 & 5,3 & 2,0 \\
\hline TOTAL & $\mathbf{2 0 , 1 3}$ & $\mathbf{1 0 0}$ & $\mathbf{5 3 , 5}$ \\
\hline
\end{tabular}

* El share no suma 100\% porque falta el resto de canales de TV abierta, cable y VHS/DVD. Fuente: Observatorio Audiovisual Peruano (OAP) y Kantar Ibope Media

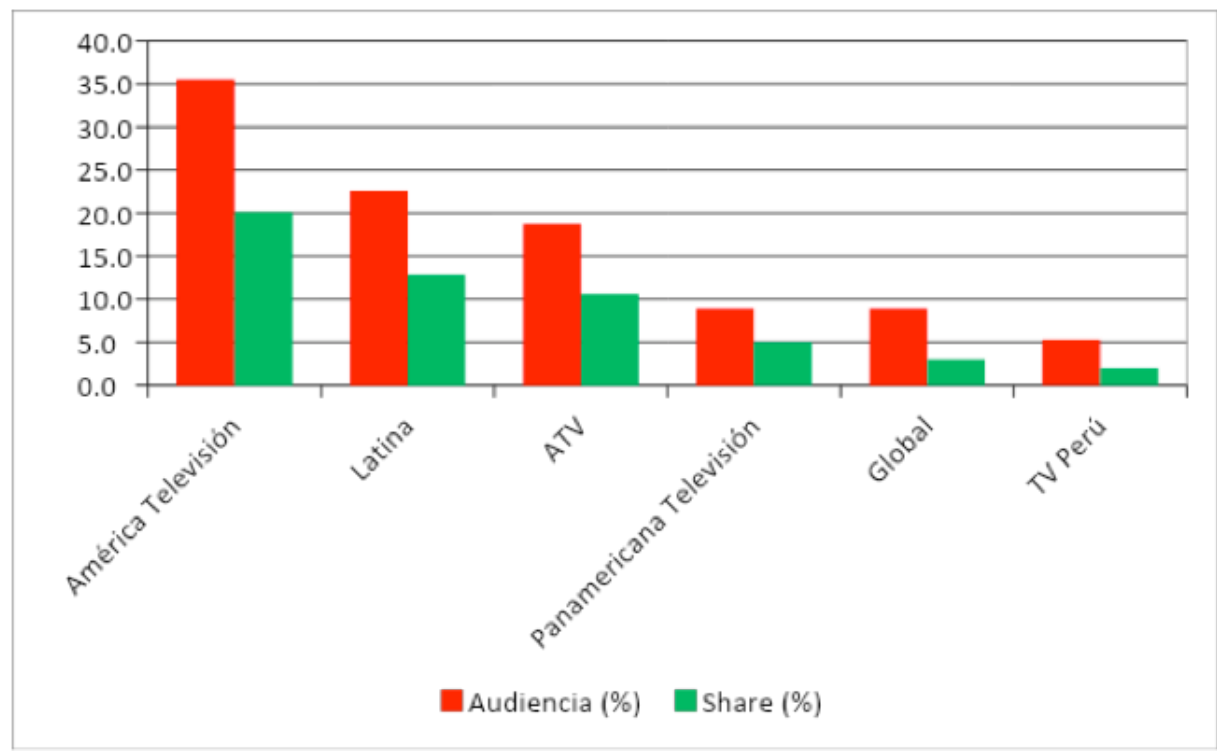

Fuente: Observatorio Audiovisual Peruano (OAP) y Kantar Ibope Media 


\section{Gráfico 2: Géneros y horas transmitidos en la programación de TV}

\begin{tabular}{|c|r|r|}
\hline $\begin{array}{c}\text { Géneros } \\
\text { transmitidos }\end{array}$ & $\begin{array}{c}\text { Horas de } \\
\text { exhibición }\end{array}$ & \begin{tabular}{c} 
\% \\
\hline Información
\end{tabular} \\
\hline Ficción & $16253: 30: 00$ & 36,53 \\
\hline Entretenimiento & $10744: 30: 00$ & 20,39 \\
\hline Religioso & $180: 30: 00$ & 0,34 \\
\hline Deporte & $840: 00: 00$ & 1,59 \\
\hline Educativo & $1980: 30: 00$ & 3,76 \\
\hline Político & $236: 30: 00$ & 0,45 \\
\hline Otros & $2968: 00: 00$ & 5,63 \\
\hline TOTAL & $\mathbf{5 2 5 6 0 : 0 0 : 0 0}$ & $\mathbf{1 0 0}$ \\
\hline
\end{tabular}

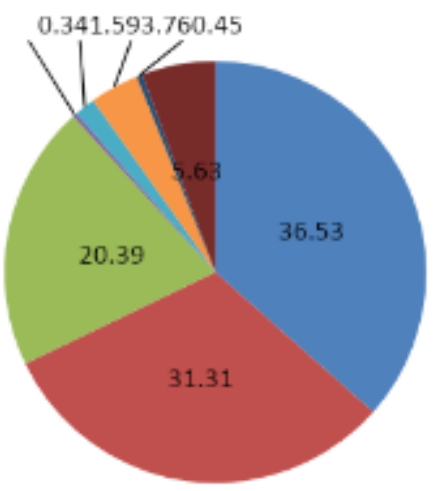

Información

Ficción

Entretenimiento

Religioso

Deporte

Educativo

Político

Otros

Fuente: Observatorio Audiovisual Peruano

Las seis cadenas de emisión nacional que observamos para este informe se mantuvieron sin cambios en la composición de propiedad. Un cambio que se observa es que la caída de audiencia de la televisión abierta registrada desde el año 2014 se detuvo, y retornó a niveles cercanos a los del 2017, esto como consecuencia del confinamiento forzado, que mantuvo en sus hogares a millones de peruanos, y que además utilizó la señal abierta para tratar de suplir la enseñanza escolar.

Si el año pasado resaltamos la caída de las horas de ficción con respecto a anuarios previos, este año de pandemia muestra el porcentaje más bajo en toda una década. La pandemia no solo redujo la cantidad de horas producidas en el país, sino que también redujo la importación o repetición de ficción. La necesidad de la población por informarse hizo que los canales llenaran las pantallas de productos informativos, género que por primera vez en lo que llevamos redactando estos anuarios logra ser el que mayor tiempo ocupó en las pantallas 
televisivas en el año. Por otro lado, la necesidad de suplir la educación escolar supuso un crecimiento en siete veces del género educativo, que deja de ocupar los últimos lugares de la tabla. Sin embargo, sus números hablan de una televisión comercial indiferente por ser un complemento a la educación, aún en épocas de crisis severa.

Si bien América Televisión mantiene el primer lugar en sintonía, su audiencia es la más baja en la última década, siendo el canal que más pérdida de público tuvo en la señal abierta durante la pandemia. Por el contrario, ATV obtuvo un repunte llegando a porcentajes de audiencia que no lograba desde el año 2015. Otro aumento notorio -aunque en niveles marginales- fue el de Global Televisión, que superó en el quinto lugar a TV Perú, algo que no sucedía desde el 2016. No sólo llama la atención la recuperación de audiencia de Global Televisión, si no la reducción de audiencia del canal estatal, que transmitió horas de información sobre la situación sanitaria, las conferencias diarias del Presidente, y muchas horas de clases escolares. Esta caída de TV Perú nos permite inferir que, si bien había mucha necesidad de conocer lo que sucedía con la pandemia, llegó un momento de saturación donde la población buscó otro tipo de contenido que no era ofrecido por el canal estatal.

En un ámbito diferente, América Televisión tuvo la satisfacción de llevarse el premio Non-English commercial of the year de los Shots Awards of the Americas. El comercial ${ }^{5}$ fue realizado basándose en la exitosa Soap opera De vuelta al Barrio, donde se planteaba la relación que se crea entre un personaje de la soap opera y una televidente, a través de la pantalla hablando de la fidelización de la audiencia. 


\subsection{La TV de pago y plataformas VoD en Perú}

Cuadro 2. Cadenas de televisión de pago en Perú

\begin{tabular}{|cl|}
\hline 10 Cadenas de TV Pago más vistas en 2020 \\
\hline 1. & Discovery Kids (Infantil) \\
2. & Cartoon Network (Infantil) \\
3. & Discovery Adults (Informativo) \\
4. & Canal N (Informativo) \\
5. & Disney Channel (Infantil) \\
6. & Disney Junior (Infantil) \\
7. & Fox Channel (Ficción) \\
8. TNT (Ficción) \\
9. TL Novelas (Ficción) \\
10. Cinecanal (Ficción)
\end{tabular}

Fuente: Observatorio Audiovisual Peruano (OAP) y Kantar Ibope Media

Perú mostró poco cambio en cuanto a las empresas proveedoras de cable. Movistar sigue siendo la líder en clientes (63\%), seguido por las empresas DirecTV (19\%) y Claro TV (8\%). Algo que generó sorpresa en la televisión de pago en el Perú fue la salida en julio de Movistar de las señales de Televisa (TL Novelas y Las Estrellas), que en años previos habían estado en los primeros lugares de rating entre los canales de cable. Incluso habiendo estado ausente medio año, TL Novelas logró ocupar el noveno lugar de audiencia entre los canales de cable. Aunque sin relación directa, no puede dejarse de indicar que en los primeros meses de confinamiento el canal de relatos de ficción turcos Kanal D Drama, registró récords de audiencia, superando a sus competidores en el Perú. 
También notoria es la presencia de Canal N, canal peruano de pago de noticias, resultado de un año en contexto de pandemia y de inestabilidad política del país, que hizo sentir una necesidad de información sobre los sucesos en el Perú.

\section{Cuadro 3. EI VoD en Perú}

Se listan las plataformas más importantes disponibles en Perú. No se incluyen los canales de YouTube de ningún operador.

\begin{tabular}{|l|l|}
\hline \multicolumn{1}{|c|}{ Principales plataformas de VoD activas en } & Total \\
\hline 1. América TV GO & \\
2. Latina Play & $\mathbf{1 8}$ \\
3. ATV Play & \\
4. TV Perú App & \\
5. Panamericana App & \\
6. HBO Go (WarnerMedia) & \\
7. Fox Play & \\
8. Fox Latinoamérica (App) & \\
9. Fox Sports (App) & \\
10. ESPN Play & \\
11. Claro Video & \\
12. Movistar Play & \\
13. DirecTV & \\
14. Fútbol Movistar & \\
15. Netflix & \\
16. Prime Video (Amazon) & \\
17. Apple TV (Apple) & \\
18. Instagram TV & \\
19. Pluto TV & \\
20. Disney+ & \\
\end{tabular}

Fuente: Observatorio Audiovisual Peruano (OAP)

La gran novedad en la oferta de VoD fue el ingreso de Disney+ en noviembre de 2020. La plataforma se suma así a la oferta de 
Netflix, Amazon, Apple TV, y a las plataformas de canales peruanos. Se ha anunciado también que la nueva plataforma de HBO Max estará disponible en junio de 2021, y meses después ingresará Paramount plus, aunque algunas de sus ofertas ya se encuentran disponibles en HBO Go y Apple TV. Igualmente, la empresa vietnamita Viettel lanzó la plataforma Bitel series + para sus usuarios, por un pago adicional al servicio de comunicación móvil.

Tres series de ficción peruanas estuvieron presentes en estas plataformas. En Movistar Play se ofertaron Aislados y Raúl con Soledad. La primera es un thriller político que mezcla la corrupción generalizada del país con la situación de pandemia, mientras la segunda es una comedia realizada por la productora Tondero, y cuenta la vida de una pareja que decide divorciarse justo en el momento en que se decreta la cuarentena total, lo que los obliga a seguir viviendo juntos y a tener que cuidarse. América TVGO ofreció Papá en Cuarentena, una comedia que narra los problemas de un irresponsable y torpe padre separado, que debe pasar la cuarentena con su pequeño hijo. Debemos indicar que Raúl con Soledad fue primero estrenada en la plataforma Netzun, mientras Papá en Cuarentena fue ofrecida primero en YouTube.

La noticia más importante para la ficción televisiva peruana con respecto al VoD, fue el estreno en Netflix de El Último Bastión, en marzo de 2021. Esta miniserie histórica producida por el canal del Estado (ver anuarios 2019 y 2020) logró mantenerse en los primeros lugares de la plataforma durante varias semanas.

\subsection{Productoras independientes de ficción televisiva}

El año 2020 fue especialmente difícil para las productoras independientes, así como para toda la industria audiovisual peruana. Aún así Del Barrio Producciones produjo La Otra Orilla y Mi Vida sin Ti (de ambas se hablará en los puntos 5 y 6), mientras ProTV produjo Princesas, todas estrenadas entre agosto y diciembre. Te Volveré a Encontrar, una telenovela producida por ProTV en el 2017 pero que 
nunca había sido estrenada, fue la que permitió seguir contando con ficción televisiva nacional en horario estelar, mientras las productoras se adecuaban a los protocolos para retomar la producción.

\subsection{Fuentes de financiamiento del sector audiovisual}

Según datos de la empresa CPI, la crisis económica generada por la pandemia significó una reducción de presupuesto de publicidad del 24,2\%, con respecto al 2019. La publicidad en televisión significó el 42,5\% de las inversiones, el porcentaje más bajo en los últimos cinco años. En contraparte, el mayor aumento de inversión publicitaria se dio en la internet, donde alcanzó el 27,1\%, mientras en 2019 tuvo una participación de 19,9\%. Las mayores caídas de inversión publicitaria se dieron en los medios impresos, que vieron reducidas estas inversiones a más de la mitad. Según CPI esto se pudo deber a las restricciones de importación de papel durante la pandemia, y al miedo al contagio por el contacto físico.

La pandemia y la crisis económica que eso trajo redujo posibilidades de financiamientos o patrocinios. Lo que sí se observó en este periodo es que el $11 \%$ de los anuncios que fueron emitidos durante cuarentena tuvieron alguna relación directa al COVID-19, marcando así las prioridades de los anunciantes.

\subsection{Políticas de comunicación}

La situación de emergencia nacional congeló cualquier política para avanzar en reformas o desarrollo de la televisión digital. El gobierno sin embargo dio facilidades para congelar o aplazar pagos de deudas y cuotas a las empresas de radiodifusión. Las normativas más importantes se dieron en cuanto a protocolos de seguridad para la realización audiovisual. En octubre de 2020 se emitió la RM 000266-2020$\mathrm{DM} / \mathrm{MC}$ que aprobó "el protocolo sanitario para la implementación de medidas de vigilancia, prevención y control frente al COVID-19 en 
las producciones de obras audiovisuales publicitarias y cinematográficas", estableciendo las recomendaciones para prevenir y controlar la propagación de la pandemia, oficializando varias de las medidas que ya habían adquirido las empresas, aunque eso significó al aumento de costos de producción, y alargó los cronogramas de rodaje.

\subsection{Infraestructura de conectividad digital y móvil}

La infraestructura digital mostró sus falencias en el país durante la pandemia. Si bien buena parte de las localidades costeras poseen conectividad móvil y digital en niveles aceptables, las localidades andinas y de la Amazonía mostraron carencias graves, sobre todo cuando se intentó suplir las clases escolares a través de medios alternativos. Un informe del Instituto Nacional de Estadística e Informática indica que en el 2020 solo el 40,1\% de los hogares del Perú tenía acceso a internet. A pesar de que esto significa un alza de 3,4\% comparado al 2019, el informe resalta que en los hogares rurales el acceso es de apenas 5,9\%.

\section{Análisis del Año: la Ficción de Estreno Nacional e Iberoameri- cana en la TV abierta}

Tabla 1. Ficciones exhibidas en 2020

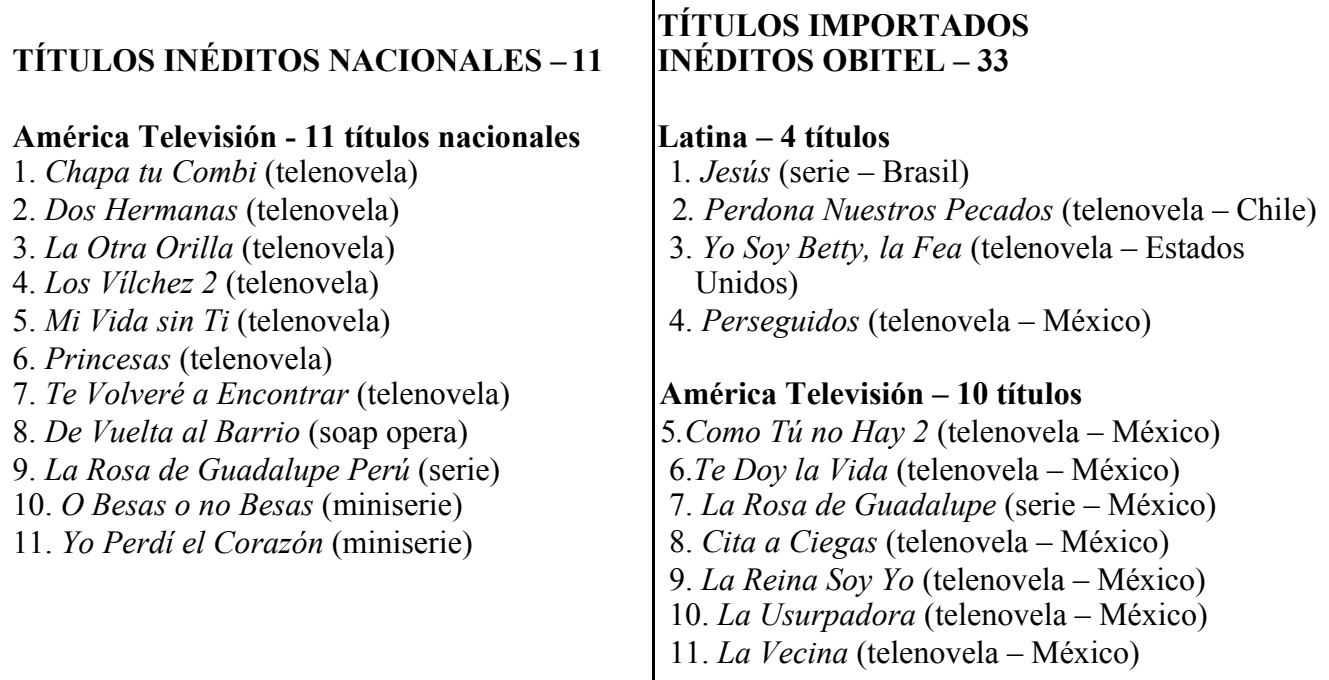

América Televisión - 10 títulos

5. Como Tú no Hay 2 (telenovela - México)

6.Te Doy la Vida (telenovela - México)

7. La Rosa de Guadalupe (serie - México)

8. Cita a Ciegas (telenovela-México)

9. La Reina Soy Yo (telenovela-México)

10. La Usurpadora (telenovela-México)

11. La Vecina (telenovela-México) 


\section{TÍTULOS INÉDITOS NACIONALES - 11 \\ COPRODUCCIONES - 5 \\ Global - 4 títulos \\ 1. Dueños del Paraíso (Estados Unidos y Chile) \\ 2. Rosario Tijeras (Estados Unidos y México) \\ 3. Rosario Tijeras 2 (Estados Unidos y México) \\ 4. Rosario Tijeras 3 (Estados Unidos y México) \\ América Televisión - 1 título \\ 5. Luis Miguel: La Serie (Estados Unidos y México)}

\section{TÍTULOS IMPORTADOS \\ INÉDITOS OBITEL - 33}

12. Mi Marido Tiene más Familia (telenovelaMéxico)

13. Soltero con Hijos (telenovela - México)

14. Sin Miedo a la Verdad (serie - México)

Panamericana Televisión -3 títulos

15. Esmeralda (telenovela - Brasil)

16. Marido en Alquiler (telenovela - Estados Unidos)

17. Dama y Obrero (telenovela - Estados Unidos)

TV Perú - 1 título

18. Golpe al Corazón (telenovela - Argentina)

ATV -8 títulos

19. La Reina del Flow (telenovela-Colombia)

20. Las Hermanitas Calle (telenovela-Colombia)

21. Las Muñecas de la Mafia 2 (telenovelaColombia)

22. Sobreviviendo a Escobar (serie - Colombia)

23. El Señor de los Cielos 7 (telenovela - Estados Unidos)

24. Cuidado con el Ángel (telenovela - México)

25. La Dueña (telenovela-México)

26. Mañana es para Siempre (telenovela - México)

Global - 7 títulos

27. El Estilista (telenovela - Colombia)

28. Gran Hotel (serie - España)

29. La Escuelita VIP (serie - México)

30. María de todos los Ángeles (serie-México)

31. Nosotros los Guapos (serie-México)

\section{TÍTULOS IMPORTADOS INÉDITOS NO} OBITEL - 7

Latina - 2 títulos

1. Fuerza de Mujer (telenovela - Turquía)

2. La Venganza de Iffet (telenovela - Turquía)

América Televisión - 1 título

3. Recuerda Cariño (telenovela - Turquía)

Panamericana Televisión - 3 títulos

4. Princesa Valiente (serie- China)

5. Amor Eterno (telenovela - Turquía)

6. Una Mujer Desconocida (telenovela-Grecia)

Global - 1 título

7. Perdóname 2 (telenovela - Turquía)

TÍTULOS REPOSICIONES - 106

TOTAL DE TÍTULOS INÉDITOS

NACIONALES: 11

TOTAL DE TÍTULOS INÉDITOS OBITEL: 36 TOTAL DE TÍTULOS INÉDITOS (NACIONAL

Y OBITEL): 47

Fuente: Observatorio Audiovisual Peruano (OAP) 
A pesar de la reducción del total de episodios producidos que se mencionó anteriormente, este 2020 vio un aumento notorio del total de títulos inéditos y reposiciones exhibidos, 153 en total. Es el mayor número obtenido en todos los años en que se ha venido monitoreando la programación peruana, a saber, desde el 2012. En el caso de reposiciones, su aumento obedece a completar el vacío de horas de programación dejadas por la suspensión de estrenos nacionales por la pandemia. Los títulos inéditos, si bien se detuvieron inicialmente, lograron retornar a la parrilla de programación hacia la segunda mitad del 2020.

Los títulos inéditos nacionales, 11 en total, se han recuperado cuantitativamente (como se detalla en el punto 5), si los comparamos a la contracción observada el 2019, cuando solo se exhibieron 8 ficciones peruanas. Hay que resaltar que este 2020, es el primer año en el que todos los títulos nacionales pertenecen al mismo canal, América Televisión, que como ya se mencionó anteriormente, se mantiene en el primer lugar de índices de audiencia, a pesar de tener menores cifras que el año 2019.

También podemos evidenciar la aparición de coproducciones entre países Obitel, lo cual no se había reportado en canales peruanos desde el 2017. La cantidad de títulos importados inéditos Obitel, 36, también ha experimentado un alza notoria, pues duplica los números del año previo que solo llegaron a 16. Lo contrario sucede con las reposiciones, ya que aquí ha habido una ligera caída comparando a los 110 títulos exhibidos el 2019. A pesar de ello, es una cifra alta contrastándola con otros años previos.

Finalmente, un dato nuevo en esta tabla es el reconocimiento de ficciones de estreno provenientes de otros países no pertenecientes a Obitel, que están presentes en los canales peruanos. Debemos aclarar que este no es un fenómeno de este último año, sino que ya se ha dado constantemente en nuestras pantallas y en las del resto de países Obitel como se reseña en los anuarios anteriores. En el caso peruano, la mayoría de estas ficciones siguen proviniendo de Turquía, tradicionalmente una fuente inusual de ficciones para nuestros canales, pero la 
búsqueda de un nuevo fenómeno de audiencia como el de las telenovelas turcas, se ha ampliado a otros horizontes como China y Grecia. Anteriormente tuvimos también en Perú, ficciones de Japón, Corea del Sur, Rumanía e India, estando algunas de ellas todavía en pantalla a modo de repeticiones.

Tabla 2: La Ficción de Estreno en 2020: Países de origen

\begin{tabular}{|l|r|r|r|r|r|r|}
\hline \multicolumn{1}{|c|}{ País } & Títulos & \% & $\begin{array}{l}\text { Capítulos/ } \\
\text { Episodios }\end{array}$ & \% & Horas & \multicolumn{1}{c|}{$\%$} \\
\hline NACIONAL (total) & $\mathbf{1 1}$ & $\mathbf{2 3 , 4}$ & $\mathbf{4 4 4}$ & $\mathbf{2 0 , 4}$ & $\mathbf{4 4 2 : 0 0 : 0 0}$ & $\mathbf{2 0 , 6}$ \\
\hline PAÍSES OBITEL (total) & $\mathbf{3 1}$ & $\mathbf{6 6 , 0}$ & $\mathbf{1 4 5 1}$ & $\mathbf{6 6 , 7}$ & $\mathbf{1 4 1 8 : 0 0 : 0 0}$ & $\mathbf{6 6 , 1}$ \\
\hline Argentina & 1 & 2,1 & 117 & 5,4 & $118: 30: 00$ & 5,5 \\
\hline Brasil & 2 & 4,3 & 112 & 5,2 & $112: 00: 00$ & 5,2 \\
\hline Chile & 1 & 2,1 & 140 & 6,4 & $128: 00: 00$ & 6,0 \\
\hline Colombia & 5 & 10,6 & 250 & 11,5 & $286: 30: 00$ & 13,4 \\
\hline Ecuador & 0 & 0,0 & 0 & 0,0 & $0: 00: 00$ & 0,0 \\
\hline España & 1 & 2,1 & 2 & 0,1 & $2: 00: 00$ & 0,1 \\
\hline EEUU (producción hispana) & 4 & 8,5 & 232 & 10,7 & $231: 30: 00$ & 10,8 \\
\hline México & 17 & 36,2 & 598 & 27,5 & $539: 30: 00$ & 25,2 \\
\hline Perú & 11 & 23,4 & 444 & 20,4 & $442: 00: 00$ & 20,6 \\
\hline Portugal & 0 & 0,0 & 0 & 0,0 & $0: 00: 00$ & 0,0 \\
\hline Uruguay & 0 & 0,0 & 0 & 0,0 & $0: 00: 00$ & 0,0 \\
\hline Venezuela & 0 & 0,0 & 0 & 0,0 & $0: 00: 00$ & 0,0 \\
\hline COPRODUCIONES (total) & $\mathbf{5}$ & $\mathbf{1 0 , 6}$ & $\mathbf{2 7 9}$ & $\mathbf{1 2 , 8}$ & $\mathbf{2 8 4 : 3 0 : 0 0}$ & $\mathbf{1 3 , 3}$ \\
\hline Coproducciones peruanas & 0 & 0,0 & 0 & 0,0 & $0: 00: 00$ & 0,0 \\
\hline Coproducciones entre países & 3 & 0,0 & 82 & 0,0 & $81: 30: 00$ & 0,0 \\
\hline Obitel & $\mathbf{4 7}$ & $\mathbf{1 0 0 , 0}$ & $\mathbf{2 1 7 4}$ & $\mathbf{1 0 0 , 0}$ & $\mathbf{2 1 4 4 : 3 0 : 0 0}$ & $\mathbf{1 0 0 , 0}$ \\
\hline TOTAL GENERAL & & & &
\end{tabular}

Fuente: Observatorio Audiovisual Peruano (OAP)

Observando el país de origen de las ficciones de estreno Obitel en el Perú, el panorama actual se presenta con el dominio cuantitativo de las ficciones mexicanas en nuestro mercado con 17 títulos, recuperando su número de títulos exhibidos en las pantallas peruanas respecto a años anteriores. 
A pesar de ello, Perú está dentro de esta lista en el segundo lugar, con 11 ficciones estrenadas. Una cifra que muestra una reacción luego de dos años de contracción. Sin embargo, tengamos en consideración que hubo títulos que vieron interrumpida su difusión por el tema COVID-19 y, además, la exhibición de tres producciones que habían pospuesto su emisión varios años o que se encontraban solo en América TVGO, como se mencionó anteriormente. Hubo vacíos que llenar en la programación y América Televisión vio la oportunidad para estrenar por señal abierta lo que tenía guardado en su catálogo.

Un segundo grupo lo componen Estados Unidos y Colombia, quienes también han visto aumentadas sus cifras, tras el bajón indicado el 2019. Ya detrás de estos casos, con mínima cantidad de títulos, Argentina, Chile, España, y especialmente Brasil, quien ha visto reducida notoriamente su presencia en pantallas peruanas en los últimos años.

Tabla 3. Formatos de la ficción nacional e iberoamericana

\begin{tabular}{|c|c|c|c|c|c|c|c|c|c|c|c|c|}
\hline \multirow{2}{*}{ Formato } & \multicolumn{6}{|c|}{ Nacionales } & \multicolumn{6}{|c|}{ Iberoamericanos } \\
\hline & Títulos & $\%$ & $\mathbf{C} / \mathbf{E}$ & $\%$ & H & $\%$ & Títulos & $\%$ & $\mathrm{C} / \mathrm{E}$ & $\%$ & $\mathbf{H}$ & $\%$ \\
\hline Telenovela & 7 & 63,6 & 347 & 78,2 & 345:00:00 & 78,1 & 27 & 75,0 & 1491 & 86,2 & $1528: 30: 00$ & 89,8 \\
\hline Serie & 1 & 9,1 & 20 & 4,5 & $20: 00: 00$ & 4,5 & 9 & 25,0 & 239 & 13,8 & $174: 00: 00$ & 10,2 \\
\hline Miniserie & 2 & 18,2 & 9 & 2,0 & 9:00:00 & 2,0 & 0 & 0,0 & 0 & 0,0 & 0:00:00 & 0,0 \\
\hline Telefilme & 0 & 0,0 & 0 & 0,0 & 0:00:00 & 0,0 & 0 & 0,0 & 0 & 0,0 & 0:00:00 & 0,0 \\
\hline Unitario & 0 & 0,0 & 0 & 0,0 & $0: 00: 00$ & 0,0 & 0 & 0,0 & 0 & 0,0 & $0: 00: 00$ & 0,0 \\
\hline Docudrama & 0 & 0,0 & 0 & 0,0 & 0:00:00 & 0,0 & 0 & 0,0 & 0 & 0,0 & 0:00:00 & 0,0 \\
\hline $\begin{array}{l}\text { Otros (soap } \\
\text { opera, etc.) }\end{array}$ & 1 & 9,1 & 68 & 15,3 & $68: 00: 00$ & 15,4 & 0 & 0,0 & 0 & 0,0 & $0: 00: 00$ & 0,0 \\
\hline Total & 11 & 100,0 & 444 & 100,0 & 442:00:00 & 100,0 & 36 & 100,0 & 1730 & 100,0 & $1702: 30: 00$ & 100,0 \\
\hline
\end{tabular}

Fuente: Observatorio Audiovisual Peruano (OAP)

El resultado general de esta tabla 3, nos lleva a considerar a la telenovela como el formato que ha mantenido su preponderancia frente a los demás. Si bien esto ha sido así mayoritariamente, hay algunas diferencias entre los resultados peruanos e iberoamericanos en estos años. Sin importar que las cantidades individuales hayan variado, en todos los últimos años, la telenovela sí se ha mantenido proporcional- 
mente como formato líder a nivel de las ficciones iberoamericanas. En el caso peruano, en cambio, ha habido una rotación entre la telenovela, la serie y la miniserie como los formatos más frecuentes entre las ficciones presentadas. Cabe resaltar la figura de la soap opera que, desde hace varios años, primero con Al Fondo Hay Sitio y ahora con De Vuelta al Barrio, se mantiene dentro de los formatos que venimos considerando en el Perú y que ha sido de los que mayor audiencia han tenido.

Tabla 4. Los 10 títulos más vistos en la televisión abierta

\begin{tabular}{|c|c|c|c|c|c|c|c|c|}
\hline \multicolumn{2}{|c|}{ Título } & Canal & Productora & $\begin{array}{c}\text { Formato } \\
\text { /Género }\end{array}$ & $\begin{array}{c}\mathbf{N}^{\circ} \text { de } \\
\text { cap. } \\
\text { /ep. } \\
\mathbf{2 0 2 0}\end{array}$ & $\begin{array}{c}\text { Franja } \\
\text { horaria }\end{array}$ & Rating & Share \\
\hline 1 & Los Vilchez 2 & $\begin{array}{c}\text { América } \\
\text { Televisión }\end{array}$ & ProTV & $\begin{array}{c}\text { Telenovela/ } \\
\text { Comedia }\end{array}$ & 68 & $\begin{array}{c}\text { Prime } \\
\text { Time }\end{array}$ & 21,4 & 31,6 \\
\hline 2 & $\begin{array}{c}\text { Chapa tu } \\
\text { Combi }\end{array}$ & $\begin{array}{c}\text { América } \\
\text { Televisión }\end{array}$ & $\begin{array}{c}\text { Del Barrio } \\
\text { Producciones }\end{array}$ & $\begin{array}{c}\text { Telenovela/ } \\
\text { Melodrama }\end{array}$ & 45 & $\begin{array}{c}\text { Prime } \\
\text { Time }\end{array}$ & 20,3 & 31,0 \\
\hline 3 & $\begin{array}{c}\text { Dos } \\
\text { Hermanas }\end{array}$ & $\begin{array}{c}\text { América } \\
\text { Televisión }\end{array}$ & $\begin{array}{c}\text { Del Barrio } \\
\text { Producciones }\end{array}$ & $\begin{array}{c}\text { Telenovela / } \\
\text { Melodrama }\end{array}$ & 12 & $\begin{array}{c}\text { Prime } \\
\text { Time }\end{array}$ & 19,9 & 29,3 \\
\hline 4 & $\begin{array}{c}\text { De Vuelta al } \\
\text { Barrio }\end{array}$ & $\begin{array}{c}\text { América } \\
\text { Televisión }\end{array}$ & $\begin{array}{c}\text { América } \\
\text { Televisión }\end{array}$ & $\begin{array}{c}\text { Soap Opera / } \\
\text { Comedia }\end{array}$ & 68 & $\begin{array}{c}\text { Prime } \\
\text { Time }\end{array}$ & 19,0 & 30,2 \\
\hline 5 & $\begin{array}{c}\text { La Rosa de } \\
\text { Guadalupe } \\
\text { Perú }\end{array}$ & $\begin{array}{c}\text { América } \\
\text { Televisión }\end{array}$ & $\begin{array}{c}\text { América } \\
\text { Televisión }\end{array}$ & $\begin{array}{c}\text { Serie / } \\
\text { Melodrama }\end{array}$ & 20 & $\begin{array}{c}\text { Prime } \\
\text { Time }\end{array}$ & 18,6 & 26,2 \\
\hline 6 & $\begin{array}{c}\text { Te Volveré a } \\
\text { Encontrar }\end{array}$ & $\begin{array}{c}\text { América } \\
\text { Televisión }\end{array}$ & ProTV & $\begin{array}{c}\text { Telenovela / } \\
\text { Melodrama }\end{array}$ & 120 & $\begin{array}{c}\text { Prime } \\
\text { Time }\end{array}$ & 18,0 & 27,2 \\
\hline 7 & $\begin{array}{c}\text { La Rosa de } \\
\text { Guadalupe }\end{array}$ & $\begin{array}{c}\text { América } \\
\text { Televisión }\end{array}$ & Televisa & $\begin{array}{c}\text { Serie/ } \\
\text { Melodrama }\end{array}$ & 17 & $\begin{array}{c}\text { Prime } \\
\text { Time }\end{array}$ & 18,0 & 29,8 \\
\hline 8 & Princesas & $\begin{array}{c}\text { América } \\
\text { Televisión }\end{array}$ & ProTV & $\begin{array}{c}\text { Telenovela/ } \\
\text { Melodrama }\end{array}$ & 22 & $\begin{array}{c}\text { Prime } \\
\text { Time }\end{array}$ & 17,9 & 29,7 \\
\hline 9 & $\begin{array}{c}\text { Mi Vida sin } \\
\text { Ti }\end{array}$ & $\begin{array}{c}\text { América } \\
\text { Televisión }\end{array}$ & $\begin{array}{c}\text { Del Barrio } \\
\text { Producciones }\end{array}$ & $\begin{array}{c}\text { Telenovela / } \\
\text { Melodrama }\end{array}$ & 40 & $\begin{array}{c}\text { Prime } \\
\text { Time }\end{array}$ & 16,1 & 25,3 \\
\hline 10 & $\begin{array}{c}\text { La Otra } \\
\text { Orilla }\end{array}$ & $\begin{array}{c}\text { América } \\
\text { Televisión }\end{array}$ & $\begin{array}{c}\text { Del Barrio } \\
\text { Producciones }\end{array}$ & $\begin{array}{c}\text { Telenovela / } \\
\text { Melodrama }\end{array}$ & 40 & $\begin{array}{c}\text { Prime } \\
\text { Time }\end{array}$ & 15,8 & 24,4 \\
\hline
\end{tabular}

Fuente: Observatorio Audiovisual Peruano (OAP) y Kantar Ibope Media

Varios aspectos por destacar en esta Tabla 4. En primer lugar, la preferencia de ficciones peruanas por encima de ficciones extranjeras, en este caso representadas por un solo título mexicano. Recordemos que es el país que más ficciones de estreno ha tenido el 2020 en el Perú, aunque como vemos, no todos han logrado ubicarse en este top ten. Todas estas diez ficciones han sido exhibidas por América Televisión, canal líder en índices de audiencia. Por otro lado, hay una pre- 
dilección notoria del melodrama por sobre la comedia, a pesar de que esta última es el género más visto, según las cifras de rating y share. Finalmente, reforzando también lo indicado en el capítulo 1, se nota en el caso de estos 10 títulos más vistos que, dichas cifras han experimentado una ligera baja si las comparamos al rating y share obtenidos hasta el año 2019.

Tabla 4A. Los 10 títulos nacionales más vistos en la televisión abierta

\begin{tabular}{|c|c|c|c|c|c|c|c|c|}
\hline \multicolumn{2}{|c|}{ Título } & Canal & Productora & $\begin{array}{c}\text { Formato } \\
\text { /Género }\end{array}$ & $\begin{array}{c}\mathbf{N}^{\circ} \text { de } \\
\text { cap. } \\
\text { /ep. } \\
\text { (2020) }\end{array}$ & $\begin{array}{c}\text { Franja } \\
\text { horaria }\end{array}$ & Rating & Share \\
\hline 1 & Los Vílchez 2 & $\begin{array}{c}\text { América } \\
\text { Televisión }\end{array}$ & ProTV & $\begin{array}{c}\text { Telenovela/ } \\
\text { Melodrama }\end{array}$ & 68 & $\begin{array}{c}\text { Prime } \\
\text { Time }\end{array}$ & 21,4 & 31,6 \\
\hline 2 & $\begin{array}{c}\text { Chapa tu } \\
\text { Combi }\end{array}$ & $\begin{array}{c}\text { América } \\
\text { Televisión }\end{array}$ & $\begin{array}{c}\text { Del Barrio } \\
\text { Producciones }\end{array}$ & $\begin{array}{c}\text { Telenovela/ } \\
\text { Melodrama }\end{array}$ & 45 & $\begin{array}{c}\text { Prime } \\
\text { Time }\end{array}$ & 20,3 & 31,0 \\
\hline 3 & $\begin{array}{c}\text { Dos } \\
\text { Hermanas }\end{array}$ & $\begin{array}{c}\text { América } \\
\text { Televisión }\end{array}$ & $\begin{array}{c}\text { Del Barrio } \\
\text { Producciones }\end{array}$ & $\begin{array}{c}\text { Telenovela / } \\
\text { Melodrama }\end{array}$ & 12 & $\begin{array}{c}\text { Prime } \\
\text { Time }\end{array}$ & 19,9 & 29,3 \\
\hline 4 & $\begin{array}{c}\text { De Vuelta al } \\
\text { Barrio }\end{array}$ & $\begin{array}{c}\text { América } \\
\text { Televisión }\end{array}$ & $\begin{array}{c}\text { América } \\
\text { Televisión }\end{array}$ & $\begin{array}{c}\text { Soap Opera / } \\
\text { Comedia }\end{array}$ & 68 & $\begin{array}{c}\text { Prime } \\
\text { Time }\end{array}$ & 19,0 & 30,2 \\
\hline 5 & $\begin{array}{c}\text { La Rosa de } \\
\text { Guadalupe } \\
\text { Perú }\end{array}$ & $\begin{array}{c}\text { América } \\
\text { Televisión }\end{array}$ & $\begin{array}{c}\text { América } \\
\text { Televisión }\end{array}$ & $\begin{array}{c}\text { Serie/ } \\
\text { Melodrama }\end{array}$ & 20 & $\begin{array}{c}\text { Prime } \\
\text { Time }\end{array}$ & 18,6 & 26,2 \\
\hline 6 & $\begin{array}{c}\text { Te Volveré a } \\
\text { Encontrar }\end{array}$ & $\begin{array}{c}\text { América } \\
\text { Televisión }\end{array}$ & ProTV & $\begin{array}{c}\text { Telenovela/ } \\
\text { Melodrama }\end{array}$ & 120 & $\begin{array}{c}\text { Prime } \\
\text { Time }\end{array}$ & 18,0 & 27,2 \\
\hline 7 & Princesas & $\begin{array}{c}\text { América } \\
\text { Televisión }\end{array}$ & ProTV & $\begin{array}{c}\text { Telenovela/ } \\
\text { Melodrama }\end{array}$ & 22 & $\begin{array}{c}\text { Prime } \\
\text { Time }\end{array}$ & 17,9 & 29,7 \\
\hline 8 & $\begin{array}{c}\text { Mi Vida sin } \\
\text { Ti }\end{array}$ & $\begin{array}{c}\text { América } \\
\text { Televisión }\end{array}$ & $\begin{array}{c}\text { Del Barrio } \\
\text { Producciones }\end{array}$ & $\begin{array}{c}\text { Telenovela/ } \\
\text { Melodrama }\end{array}$ & 40 & $\begin{array}{c}\text { Prime } \\
\text { Time }\end{array}$ & 16,1 & 25,3 \\
\hline 9 & $\begin{array}{c}\text { La Otra } \\
\text { Orilla }\end{array}$ & $\begin{array}{c}\text { América } \\
\text { Televisión }\end{array}$ & $\begin{array}{c}\text { Del Barrio } \\
\text { Producciones }\end{array}$ & $\begin{array}{c}\text { Telenovela/ } \\
\text { Melodrama }\end{array}$ & 40 & $\begin{array}{c}\text { Prime } \\
\text { Time }\end{array}$ & 15,8 & 24,4 \\
\hline 10 & $\begin{array}{c}\text { Yo perdí el } \\
\text { Corazón }\end{array}$ & $\begin{array}{c}\text { América } \\
\text { Televisión }\end{array}$ & $\begin{array}{c}\text { Tercer Ojo } \\
\text { Producciones }\end{array}$ & $\begin{array}{c}\text { Miniserie/ } \\
\text { Melodrama }\end{array}$ & 4 & Nocturno & 3,4 & 13,8 \\
\hline
\end{tabular}

Fuente: Observatorio Audiovisual Peruano (OAP) y Kantar Ibope Media

Si bien esta tabla es muy similar a la anterior, al ser solo de títulos de estreno peruanos, podemos encontrar al final de esta el ingreso de Yo Perdí el Corazón, la única ficción que ha sido realizada por una productora distinta a las tres con las que mayoritariamente trabaja América Televisión. Otra consideración va por el horario de emisión, pues va fuera del prime time, a saber, a partir de las 00:00 horas una vez por semana, contrariamente a la frecuencia de emisión diaria a la que está acostumbrado el espectador peruano, lo cual incide también en sus bajas cifras de rating y share respecto a las demás ficciones. 
TABLA 5. Perfil de audiencia de los 10 títulos más vistos: género, edad, nivel socioeconómico.

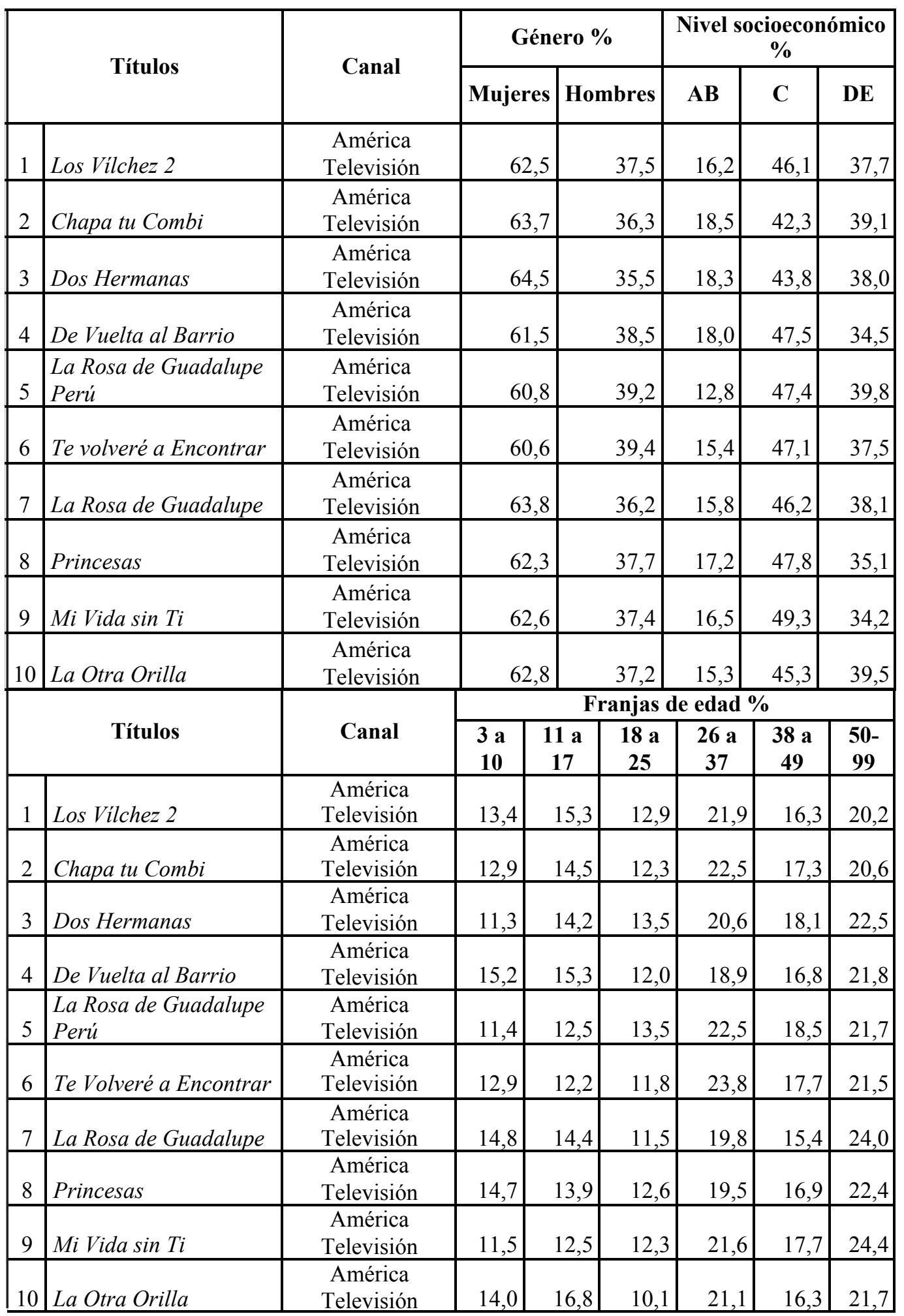

Fuente: Observatorio Audiovisual Peruano (OAP) y Kantar Ibope Media 
Estas últimas tablas, que exponen el desagregado por género, nivel socioeconómico y edades, no han mostrado mayores sorpresas respecto a cómo se plantea el público objetivo para los canales de televisión peruanos en general. En el primer caso, se confirma la idea de que la televisión peruana está pensando con sus ficciones, principalmente, en el grupo de mujeres y de nivel socioeconómico C y DE. Todas las ficciones más vistas se han adaptado a responder a esta segmentación de forma muy ordenada. No hemos tenido casos, como el año 2019, en los que la composición de género o nivel socioeconómico muestre una redistribución de estos entre los 10 títulos con mayor índice de audiencia.

Finalmente, podríamos afirmar a partir de la última tabla que, el top ten de las ficciones peruanas son mayormente consumidas por espectadores a partir de los 26 años y en particular, por los rangos de edades entre 26 a 37 y 50 a 99 años. Estos dos últimos rangos van intercambiando su liderato entre títulos, aunque tiende a ser el rango de mayor edad el que termina teniendo una ligera preponderancia. Los rangos de edad por debajo de los 25 años, probablemente, orientan cada vez más su interés en la ficción en otros espacios con contenidos más diversos como los que se ofrecen desde las plataformas VoD.

\section{Monitoreo VoD 2020}

Durante el 2020, las plataformas internacionales de contenidos audiovisuales como Netflix, Prime Video, etc., potenciaron su presencia y pudieron hacer frente a la demanda aparecida durante este tiempo. No sucedió lo mismo con las plataformas de las televisoras locales, cuya producción es ínfima respecto a sus contrapartes internacionales. 


\subsection{Mercado de plataformas de VoD}

América TVGO, la plataforma VoD peruana más importante del país, todavía no reditúa ingresos competitivos respecto al broadcasting. Según Éric Jürgensen, ex CEO de América Televisión, "Sabemos que tenemos que estar presentes y es un complemento de la TV tradicional, pero es un mundo que por ahora no genera dinero. Hoy el ingreso digital total representa entre el 2 y el $4 \%$ total de los ingresos de los canales de TV"6. Esto puede explicarse, en parte, debido a que la televisión de señal abierta sigue manteniéndose como el principal medio de comunicación en nuestro país, pero también porque la oferta en plataformas locales es limitada. No se puede apreciar todavía una ventaja diferencial, además del costo para acceder completamente a sus contenidos. De pronto, el valor de lo local puede ser un factor por explotar en el caso de las plataformas peruanas, para encontrar ahí, esa ventaja diferencial ante las plataformas extranjeras. Movistar Play, que depende de un canal de cable, ha empezado, desde el 2019 en el Perú, a producir contenido local. Sin embargo, se trata de ficciones limitadas en títulos y con pocos capítulos.

Caso contrario, sucedió con el VoD desde plataformas internacionales. De acuerdo con un estudio realizado por Sherlock Communications, "el $22 \%$ de los peruanos usa cuatro o más servicios de streaming. Además, durante la pandemia del COVID-19, el $83 \%$ de los usuarios encuestados se suscribió a una plataforma de video"7. Este panorama coloca a nuestro país y a México por encima del promedio regional, que es de dos suscripciones. De manera similar, Digital TV Research cambió sus proyecciones de crecimiento de suscripciones a plataformas VoD en la región a principios del 2020: “En marzo, (...)

6 Fuente: https://www.produ.com/noticias/ingreso-digital-epresenta-solo-entre-el-2-y-el4-total-de-los-ingresos-de-los-canales-de-tv-eric-jurgensen-de-americatv?fbclid=IwAR0YC-nX1XdPBgg6vdDMOSTRExLOdtdodJqx8OfQRqjOeXXiKyz92gDYLIU

7 Fuente: https://andina.pe/agencia/noticia-el-22-peruanos-usa-cuatro-servicios-streaming-video-segun-estudio-822489.aspx 
estimó que las suscripciones a servicios de transmisión en América Latina aumentarían de 42 millones a fines de 2019, a 81 millones en 2025. En septiembre, esa proyección se revisó a 100.3 millones durante el mismo período de cinco años"».

\subsection{Análisis del VoD en 2020: la ficción de estreno nacional e ibe- roamericana}

Tabla 6. Ficciones nacionales e iberoamericanas exhibidas en 2020 en sistemas de VoD

\begin{tabular}{|c|c|c|}
\hline $\begin{array}{l}\text { TÍTULOS } \\
\text { NACIONALES DE } \\
\text { ESTRENO }\end{array}$ & $\begin{array}{l}\text { TÍTULOS } \\
\text { IBEROAMERICANOS DE } \\
\text { ESTRENO }\end{array}$ & COPRODUCCIONES \\
\hline $\begin{array}{l}\text { Movistar Play - } 2 \text { títulos } \\
\text { nacionales } \\
\text { 1. Aislados-La Serie } \\
\text { (serie) } \\
\text { 2. Raúl con Soledad } \\
\text { (serie) } \\
\text { América TVGO - } 1 \\
\text { título nacional } \\
\text { 3. Papá en Cuarentena } \\
\text { (serie) }\end{array}$ & $\begin{array}{l}\text { Netflix - } \mathbf{3 3} \text { títulos } \\
\text { iberoamericanos } \\
\text { 1. Oscuro Deseo (serie - } \\
\text { México) } \\
\text { 2. Historia de un Crimen: La } \\
\text { Búsqueda (miniserie - México) } \\
\text { 3. El Robo del Siglo (miniserie - } \\
\text { Colombia) } \\
\text { 4. Control Z (serie - México) } \\
\text { 5. Chichipatos (serie - } \\
\text { Colombia) } \\
\text { 6. Omnisciente (serie - Brasil) } \\
\text { 7. Coisa Mais Linda (serie - } \\
\text { Brasil) } \\
\text { 8. Desenfrenadas (serie - } \\
\text { México) } \\
\text { 9. Amar y Vivir (serie - } \\
\text { Colombia) } \\
\text { 10. La Venganza de Analia } \\
\text { (serie - Colombia) } \\
\text { 11. El Dragón: El Regreso de } \\
\text { un Guerrero (telenovela - } \\
\text { México) } \\
\text { 12. La Casa de las Flores - } \\
\text { temporada } 3 \text { (serie - México) } \\
\text { 13. Narcos: México (serie - } \\
\text { México) } \\
\text { 14. El Desorden que Dejas }\end{array}$ & $\begin{array}{l}\text { Netflix - } \mathbf{2} \text { títulos } \\
\text { 1. Alguien Tiene que Morir } \\
\text { (miniserie - España, } \\
\text { México) } \\
\text { 2. Selena: La Serie (serie - } \\
\text { EE. UU., México) }\end{array}$ \\
\hline
\end{tabular}

8 Fuente: https://gestion.pe/economia/el-83-de-peruanos-contrato-su-primer-servicio-destreaming-este-ano-afirma-estudio-nndc-noticia/?ref=gesr 


\begin{tabular}{|c|c|c|}
\hline $\begin{array}{l}\text { TÍTULOS NACIONALES } \\
\text { DE ESTRENO }\end{array}$ & $\begin{array}{l}\text { TÍTULOS } \\
\text { IBEROAMERICANOS DE } \\
\text { ESTRENO }\end{array}$ & COPRODUCCIONES \\
\hline & $\begin{array}{l}\text { 15. 100 Días para } \\
\text { Enamorarnos } \\
\text { (telenovela - EE. UU.) } \\
\text { 16. Enemigo Íntimo } \\
\text { (serie - México) } \\
\text { 17. Vis a Vis: El Oasis } \\
\text { (serie - España) } \\
\text { 18. La Valla (serie - España) } \\
\text { 19. El Reto del Beso } \\
\text { (serie - Brasil) } \\
\text { 20. No Te Puedes Esconder } \\
\text { (serie - EE. UU.) } \\
\text { 21. Reality Z (serie - Brasil) } \\
\text { 22. Buenos Días Verônica } \\
\text { (serie - Brasil) } \\
\text { 23. La Reina de las Indias y el } \\
\text { Conquistador } \\
\text { (serie - Colombia) } \\
\text { 24. Los Favoritos de Midas } \\
\text { (miniserie - España) } \\
\text { 25. Perdida (serie - España) } \\
\text { 26. Valeria (serie - España) } \\
\text { 27. Vivir Sin Permiso - } \\
\text { temporada 2 (serie - España) } \\
\text { 28. Las Chicas del Cable - } \\
\text { temporada } 5 \text { (serie - España) } \\
\text { 29. Alta Mar - temporada } 3 \\
\text { (serie - España) } \\
\text { 30. Toy Boy (serie - España) } \\
\text { 31. Casi Feliz } \\
\text { (serie - Argentina) } \\
\text { 32. Puerta } 7 \text { (serie - Argentina) } \\
\text { 33. Siempre Bruja } \\
\text { (serie - Colombia) } \\
\text { Prime Video - 3 títulos } \\
\text { iberoamericanos } \\
\text { 34. De Brutas, Nada } \\
\text { (serie - México) } \\
\text { 35. Backdoor (serie - México) } \\
\text { 36. Pequeñas Coincidencias } \\
\text { (serie - España) }\end{array}$ & \\
\hline \multicolumn{3}{|l|}{ TOTAL GENERAL: 41} \\
\hline Total: 3 & Total: 36 & Total: 2 \\
\hline
\end{tabular}

Fuente: Observatorio Audiovisual Peruano 
Al igual que el 2019, este 2020 trajo consigo tres títulos peruanos de estreno en VoD. En esta oportunidad, ya no son todos de Movistar Play, sino que América TVGO también aporta.

Por otro lado, vale la pena señalar que los títulos iberoamericanos de estreno han visto reducirse su cifra total a 36 respecto de los 41 que se encontraron el 2019. Esta caída se relaciona directamente con el estancamiento de las actividades audiovisuales, en general, a causa de la pandemia.

Tabla 7. La ficción de estreno en 2020 en VoD: países de origen

\begin{tabular}{|l|r|r|}
\hline \multicolumn{1}{|c|}{ País } & Títulos & \multicolumn{1}{c|}{$\%$} \\
\hline NACIONAL (total) & $\mathbf{3}$ & $\mathbf{7 , 3 2}$ \\
\hline PAíSES OBITEL (total) & $\mathbf{3 6}$ & $\mathbf{8 7 , 8 0}$ \\
\hline Argentina & 2 & 4,88 \\
\hline Brasil & 5 & 12,20 \\
\hline Chile & 0 & 0 \\
\hline Colombia & 6 & 0 \\
\hline Ecuador & 0 & 0 \\
\hline España & 11 & 26,83 \\
\hline EE.UU. (producción hispánica) & 2 & 4,88 \\
\hline México & 10 & 24,39 \\
\hline Perú & 3 & 7,32 \\
\hline Portugal & 0 & 0 \\
\hline Uruguay & 0 & 0 \\
\hline Venezuela & 0 & 0 \\
\hline COPRODUCCIONES (total) & $\mathbf{2}$ & $\mathbf{4 , 8 8}$ \\
\hline Coproducciones peruanas & $\mathbf{0}$ & 0 \\
\hline Coproducciones entre países OBITEL & $\mathbf{2}$ & 4,88 \\
\hline TOTAL GENERAL & $\mathbf{4 1}$ & $\mathbf{1 0 0 , 0 0}$ \\
\hline
\end{tabular}

Fuente: Observatorio Audiovisual Peruano (OAP)

Lo más resaltante de este cuadro, tiene que ver con la caída en el total de títulos iberoamericanos de estreno en VoD que pudieron ser 
vistos en el Perú, de 41 el 2019 a 36 para el 2020. De ellos, Argentina y Brasil vieron sus cifras reducidas a menos de la mitad. Otro país con un ligero descenso fue España, que redujo en dos el número de sus producciones para alcanzar solo 11 estrenos.

Colombia y México, en cambio, mostraron una recuperación en cuanto al número de títulos, Colombia llega este 2020 a seis estrenos. Y México pasa a estrenar diez títulos. Veremos cómo se recompone el panorama para este 2021, teniendo en cuenta la reactivación del sector audiovisual, aunque con los condicionamientos económicos que la pandemia ha dejado en canales, productoras y plataformas.

\section{Ficción y participación de las audiencias en entornos digitales.}

Como mencionamos en el anuario anterior (Cassano, Dettleff, \& Vásquez, 2020), la violencia de género es una realidad desalentadora que desangra al país. Solo durante la cuarentena obligatoria por la pandemia del COVID-19, la cifra de mujeres desaparecidas superó los 900 casos, fueron 35 los feminicidios y más de 600 niñas y adolescentes mujeres fueron víctimas de violencia sexual.

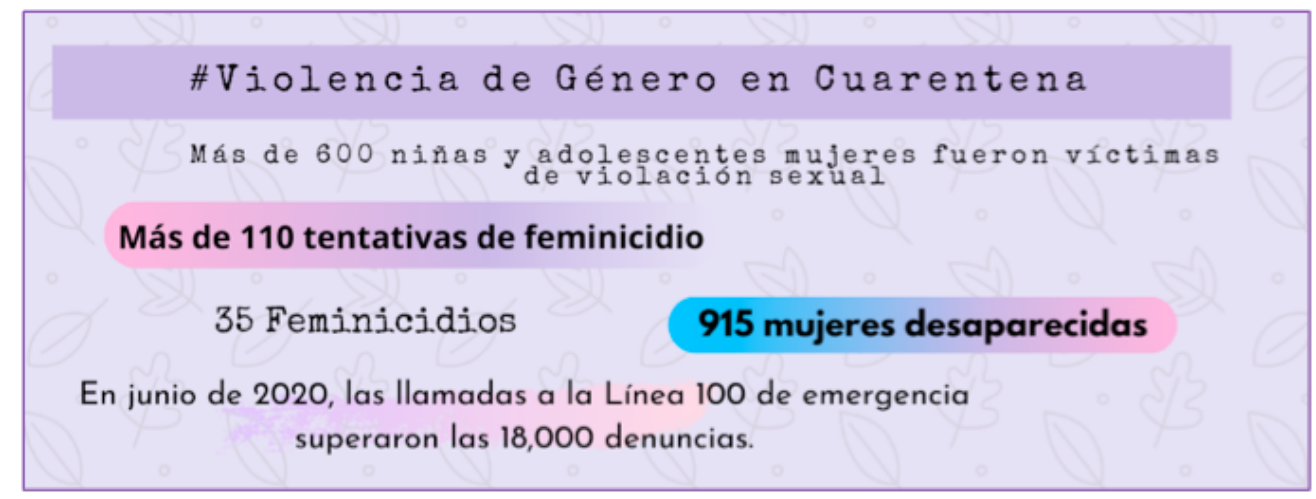

Fuentes: https://violentadasencuarentena.distintaslatitudes.net/portfolio/peru/ y El Comercio ${ }^{9}$ Elaboración propia.

Como podemos observar, las mujeres peruanas han sido violentadas y la gran mayoría de estos hechos de violencia han ocurrido 
al interior de los hogares. Podemos reconocer en estos hechos aquello que Rita Segato denomina la "violencia expresiva", aquella donde las mujeres funcionan como lienzo, como bastidor y como territorio para establecer los términos de una contienda particular (Segato, 2014).

Estas cifras concretizan también la presencia de una "cultura de la violación" (Segato, 2003) que resulta de la construcción de la masculinidad como "mandato". Este mandato es el que se encuentra en la base de toda violencia ejercida sobre las mujeres y otros grupos de población (LGTBIQ+ y niños especialmente). La violencia de género así manifiesta, es una forma de normar sobre los cuerpos femeninos, un acto disciplinador y vengador contra una mujer genéricamente abordada. Un acto que se ampara en el mandato de punir y retirarle su vitalidad a una mujer percibida como desacatando y abandonando la posición a ella destinada en el sistema de estatus de la moral tradicional (Cavieres y Salinas, 1991).

Esta realidad ha sido recogida por la ficción nacional en años recientes ${ }^{10}$-Valiente Amor (2016), Mujercitas (2017), Ojitos Hechiceros (2018), En la Piel de Alicia (2019). En 2020, la telenovela Mi Vida sin Ti (2020), realizada por Del Barrio Producciones tomó el tema como eje central del relato, visibilizando las diversas formas de violencia de género contra las mujeres -psicológica, física, simbólica, económica- y exponiendo las diversas situaciones en las que estas se manifiestan. La historia de amor de Amanda y Santiago sirvió para iluminar distintas expresiones de violencia de género.

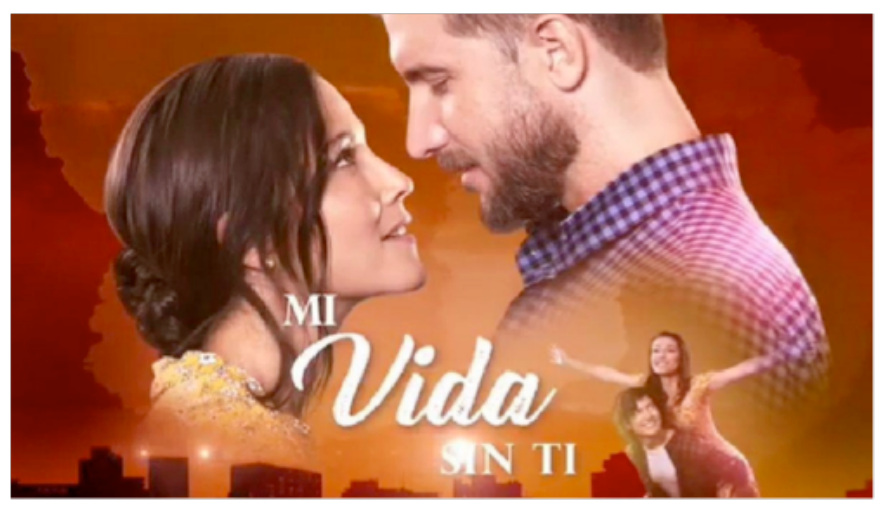

Fuente: Del barrio producciones 2020

10 Puede revisarse los capítulos peruanos de los anuarios anteriores 
Este relato generó discusión en redes, participación activa de las actrices y los actores haciendo presentaciones en vivo en diferentes medios sociales para sensibilizar a la población sobre un conjunto de actitudes, prácticas e ideas normalizadas en nuestra sociedad. Una de las primeras situaciones que generó diálogo y discusión en redes fue disparada cuando el personaje de Enrique toca el cuerpo de Olenka sin su consentimiento. Y Olenka le responde.

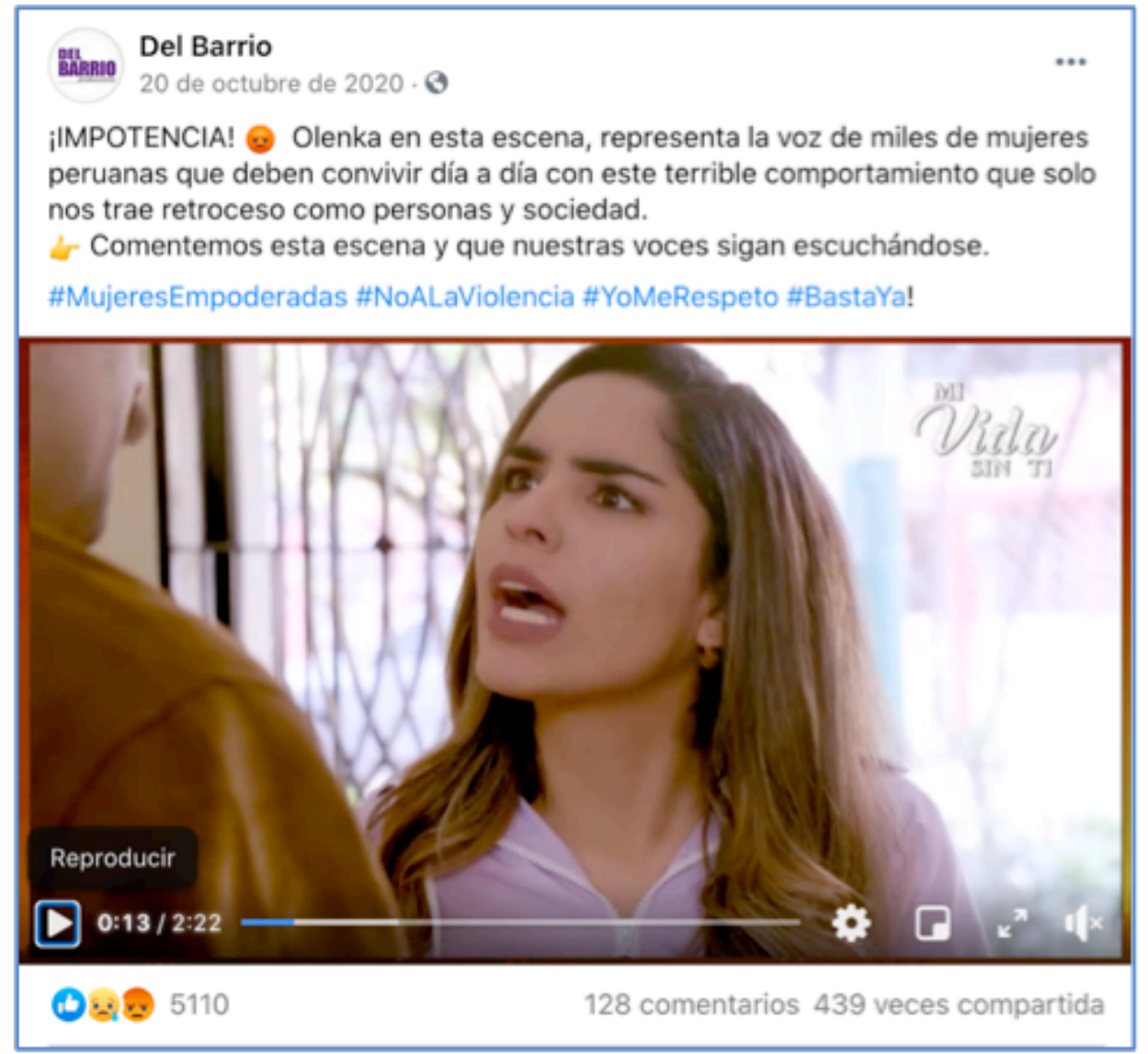

Facebook Del barrio producciones 20 de octubre de 2020

Esta escena fue compartida más de 400 veces en Facebook y 300 veces en Instagram. Muchos de los comentarios giraban en torno a la necesidad de criar a hijas e hijos con sentido de respeto y cuidado por la integridad de los cuerpos femeninos, y especialmente a respetar la voz de las mujeres cuando dicen NO. 
Justina Zavaleta

Exelente escena!

Tenemos que criar hijas fuertes que se hagan respetar, que pongan límites, que no se dejen pisotear, que sepan el valor que tiene y que lo pueden todo!

Y criar hijos respetuosos con las mujeres y niños, explicarles sobre su sexualidad y cuando una chica dice no es no y punto ! .

Tenemos una gran responsabilidad como padres para que cambien estás situaciones tan desagradables .

No soy una pro aborto!

Pero soy una feminista que como esa escena y muchas más que se vive a diario eh pasado cosas así.

Y las leyes tienen que respaldarnos

Me gusta $\cdot$ Responder $\cdot 23$ sem

Facebook Del barrio producciones 21 de octubre de 2020

Esta escena, además, fue central en el relato pues la situación representada es la misma que experimentan las mujeres de cualquier edad, clase social, grupo cultural y étnico en el país; por ello también movilizó diversas emociones y permitió compartir experiencias y diferentes formas de resiliencia. La propia actriz Daniela Feijoó -que da vida a Olenka en la ficción- señaló que "sentía que era una escena muy importante y que Olenka en ese momento representaba las voces de miles de mujeres que tenemos que batallar con esta realidad tan despreciable"'11

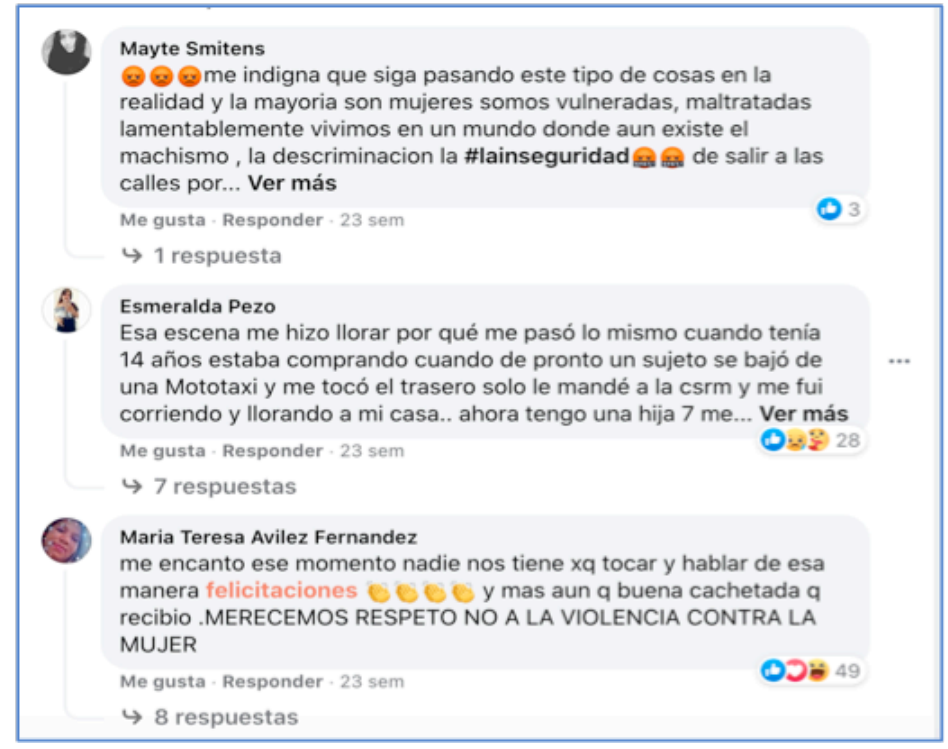

11 Se puede acceder al video completo en: https://www.facebook.com/DelBarrioPro/ posts/3308323652537851. 
Esmeralda Pezo

Esa escena me hizo llorar por qué me pasó lo mismo cuando tenía 14 años estaba comprando cuando de pronto un sujeto se bajó de una Mototaxi y me tocó el trasero solo le mandé a la csrm y me fui corriendo y llorando a mi casa.. ahora tengo una hija 7 me... Ver más Me gusta - Responder - 23 sem

$\hookrightarrow 7$ respuestas

Maria Teresa Avilez Fernandez

me encanto ese momento nadie nos tiene xq tocar $y$ hablar de esa manera felicitaciones $\mathrm{CSOS}$ y mas aun q buena cachetada q recibio .MERECEMOS RESPETO NO A LA VIOLENCIA CONTRA LA MUJER

Me gusta - Responder $\cdot 23$ sem

$\hookrightarrow 8$ respuestas

Facebook Del barrio producciones 20 de octubre de 2020

La reflexión de Daniela Feijoó también hace un llamado a no tolerar más: “indignación, bronca, rabia, pero a la vez mucha fuerza para enfrentarnos y no tolerar más...basta ya" ${ }^{12}$

\section{Mayra Victoria}

\#BastaYa de que nos vean como un objeto... Como un cuerpo que pueden tocar cuando se les da la gana.... \#BastaYa de hombres con ese machismo cavernario que piensan que nos van atemorizar o minimizar por la fuerza que ejercen hacia nosotras.... Pues, No señores... Somos mujeres decididas y fuertes capaces de todo... Me gusta - Responder $\cdot 22$ sem

Facebook Del barrio producciones 20 de octubre de 2020

De hecho, el hashtag \#BastaYa tuvo mucha movilidad en redes mientras la telenovela fue emitida.

Otro momento de gran tensión y diálogo social se dio cuando Enrique golpea a Amanda porque esta le pide explicaciones por el impedimento de Enrique de dejar estudiar a su hija Camila ${ }^{13}$.

12 Ibidem

13 La escena se puede ver en el siguiente enlace: https://www.facebook.com/DelBarrioPro/posts/3313970871973129 


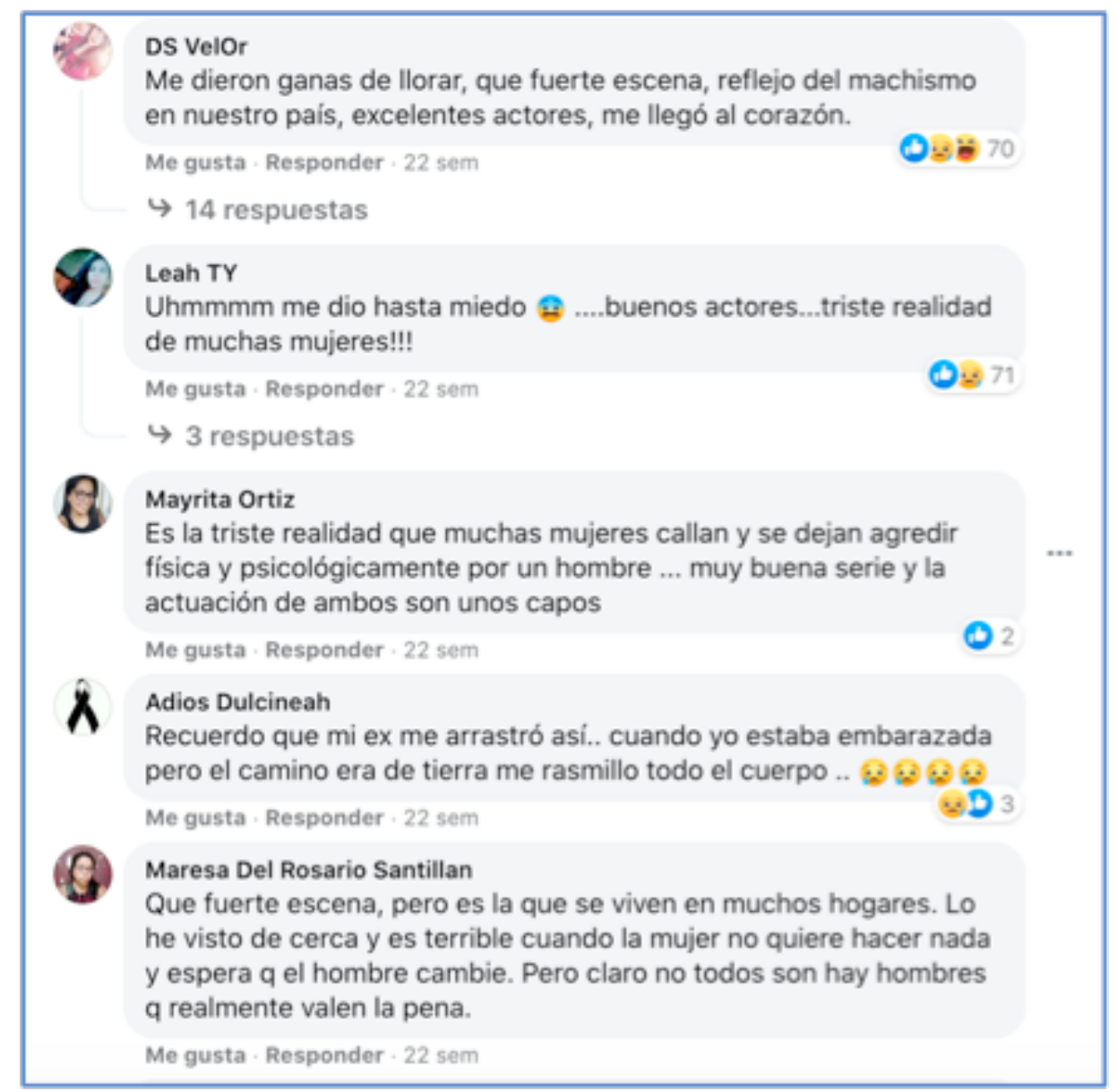

Facebook Del Barrio Producciones del 26 de octubre de 2020

Esta escena fue reproducida en Facebook más de 12,000 veces e hizo posible un diálogo abierto sobre la violencia de género contra las mujeres; en muchos de los comentarios, la audiencia planteaba situaciones similares experimentadas por ellas mismas o conocidas, proponía posibles soluciones, y también discutía sobre las responsabilidades de mujeres y hombres en estas situaciones de violencia. Para las voces que compartían sus experiencias, en la mayoría de los casos, la plataforma digital se convirtió en un espacio sororo. Aunque también es importante señalar que no faltaron los comentarios machistas que volvían a responsabilizar a las mujeres de la violencia que sufren.

Un tercer momento importante de la ficción ocurrió cuando los actores Sebastián Monteghirfo y Diego Pérez hicieron una presen- 
tación en redes reflexionando sobre las acciones que realizaban sus respectivos personajes ${ }^{14}$ de la ficción, este fue un ejercicio importante porque ambos actores hacían un llamado a cuestionarse prácticas e ideas naturalizadas por muchos hombres y mujeres que ven en los cuerpos femeninos un campo de disputa.

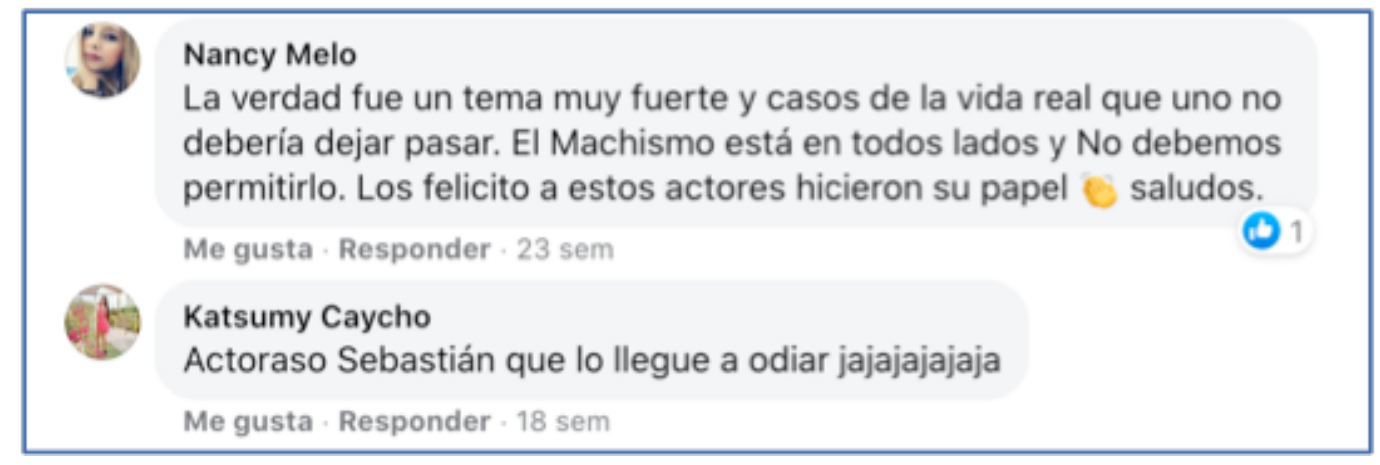

Facebook Del Barrio Producciones del 26 de octubre de 2020

Sabemos que la problemática de la violencia contra las mujeres no es una situación nueva, lo que sí es reciente es la preocupación social por las mujeres que sufren agresiones físicas, sexuales y psicológicas en el medio familiar, laboral y educacional. Hoy la evaluación de la violencia como algo negativo, en cualquiera de sus expresiones en la vida social está cada vez más generalizada, y la ficción televisiva peruana está haciendo un aporte significativo a esa visibilización y cuestionamiento.

\section{Lo Más Destacado del Año}

La emergencia sanitaria mundial generada por la Covid-19 afectó al Perú de una manera muy dramática, convirtiéndolo en el país con mayor porcentaje de muertos en el mundo con respecto a su población. Sin poder producir otro tipo de programas por las restricciones sanitarias, la primera respuesta de los canales de televisión fue llenar 
sus pantallas con noticieros e información sobre la enfermedad y las medidas adoptadas por el gobierno. Se hizo frecuente que el Presidente Vizcarra diera conferencias de prensa informando la situación del país, y anunciando medidas de contención. Varios programas de entretenimiento fueron retornando a la programación regular, pero modificando sus contenidos hacia lo informativo y la ayuda social.

El confinamiento obligatorio hizo que el gobierno buscara alternativas para que los escolares pudieran recibir educación a distancia, creando el proyecto Aprendo en Casa, para ser emitido por radio y televisión. Sin embargo, las empresas privadas de radiodifusión no se sumaron a esta iniciativa, y apenas si brindaron una o dos horas diarias de su programación, luego de varios días de negociaciones con el gobierno. Solamente las emisoras del Estado y las empresas de radiodifusión local dedicaron diferentes horarios para transmitir las clases a distancia, y la televisión se convirtió en la fuente de la educación escolar para el 46\% de los y las peruanos en el 2020 .

En marzo América Televisión, el principal canal de ficciones nacionales, finalizó la emisión de sus novelas en prime time Los Vílchez 2 y Chapa tu Combi, pero sus otras producciones del año tuvieron que ser canceladas o postergadas. El mismo día que se anunció el confinamiento obligatorio, Del Barrio Producciones informó que suspendía la grabación de su novela Dos Hermanas, y pocos días después se anunciaba que dejaría de emitirse, luego de siete episodios al aire. La cuarta temporada de la soap opera de América Televisión De Vuelta al Barrio tuvo que ser postergada hasta septiembre.

Durante el confinamiento obligatorio se dieron algunos esfuerzos individuales para producir ficción, y distribuirla en otros medios. En mayo el productor televisivo Marco Moscoso estrenó su ficción Angustia, que narra los intentos de un grupo de personas de encontrar a un adulto mayor que se escapa de la casa de reposo, en pleno confinamiento. Ese mismo mes se estrenó Miitin, webserie cómica de 12 capítulos dirigidos por Daniel Rodríguez -director de la exitosa $A j$ 
Zombies $^{15}$ - que se enfoca en los problemas del teletrabajo. Igualmente se produjo Aislados, que se estrenó a fines de noviembre a través de Movistar Play. Esta serie de 10 capítulos dirigida por Gino Tassara mezcla el drama policial con los temas de corrupción política, en plena época de pandemia, como indicamos en la sección 1.2.

La producción de nueva ficción televisiva recién se inició en Julio, y en Agosto se estrenó La Otra Orilla, producción que tocaba directamente la situación de emergencia sanitaria, y posteriormente $\mathrm{Mi}$ Vida sin Ti -además de la ya mencionada De Vuelta al Barrio-, de la cuales hablaremos en el siguiente punto. Para suplir la ausencia de ficción en prime time (franja dedicada por América Televisión a la ficción nacional), el canal emitió Te Volveré a Encontrar, una telenovela producida en el 2017, a la que se le adicionaron intervenciones de los actores al final de los capítulos, donde reflexionaban sobre la pandemia y finalizaban diciendo "Regresemos a un mundo mejor", frase utilizada por el canal durante varios meses. Pero esta no fue la única ficción que el canal recuperó de sus archivos. O Besas o no Besas y Yo Perdi el Corazón son dos ficciones producidas por América Televisión, y que debieron estrenarse en los años 2014 y 2015, y por diferentes motivos no se emitieron por la señal abierta. El canal posteriormente las hizo disponibles en su plataforma de pago América TVGO en el año $2018^{16}$, pero en el 2020 fueron emitidas por señal abierta, aunque no en horario prime time. Esto muestra la necesidad de contar con ficción en la parrilla de programación, un tipo de relato que cala bastante bien en el público peruano, pero que tenía las limitaciones más serias para ser producido.

Los primeros meses de confinamiento obligatorio llevó a buena parte de la población a consumir televisión como fuente de información o de entretenimiento, y por este motivo el consumo de este medio aumentó en $42 \%$, el mayor crecimiento en América Latina según datos 
de Kantar Ibope Media. Sin embargo, en los meses siguientes, con medidas sanitarias que no finalizaban, crisis económica y una sensación de hartazgo de parte de la población, el consumo fue disminuyendo hasta estabilizarse en los meses finales del año. Lo informativo empezó a retroceder en cuanto a presencia en las pantallas televisivas peruanas, y eso llevó a buscar formas de generar productos de ficción en medio de las restricciones sanitarias. De eso hablamos en el siguiente punto.

\section{Tema del año: Ficción en tiempos de pandemia en Perú}

Los primeros meses de 2020 el mundo se conmocionó con las imágenes de los efectos del COVID-19; primero China, luego Europa y finalmente en América el mundo se fue convirtiendo en un lugar incierto. El 11 de marzo de 2020 la Organización Mundial de la Salud (OMS) declaró el brote de la enfermedad como una pandemia global que significó confinamientos, cuidados extremos y cierres de fronteras. La vida como la conocíamos cambiaba frente a nuestros ojos.

En América Latina la pandemia global del COVID-19 ha visibilizado los populismos de derecha e izquierda con poca seriedad en el manejo de la pandemia; también la fragilidad de nuestras naciones, con ausencias estructurales y persistencias de inequidad que han devenido en situaciones dramáticas. Al momento de escribir este capítulo ${ }^{17}$, el Perú bordea el 1'540,000 casos con una cifra de fallecidos oficiales que supera los 52,000 decesos. La data de exceso de muertes del SI$\mathrm{NADEF}^{18}$ habla de más de 100,000 muertos en un año de pandemia.

En este contexto, la industria audiovisual peruana se detuvo abruptamente, siguiendo el rastro de lo acontecido en todo el mundo. Ahora bien, la vida en confinamiento y encierro aumentó de manera exponencial el consumo televisivo y de producciones audiovisuales en distintas pantallas y plataformas, además del consumo de redes socia-

17 Abril de 2021.

18 Sistema Nacional de Defunciones del Perú 
les. No sólo había necesidad de información sobre la nueva enfermedad sino principalmente de producciones de ficción, de entretenimiento, de contenidos educativos. Ante la imposibilidad de mantener las escuelas abiertas, la televisión y la radio se convirtieron en nuestro país en la única posibilidad de compartir material educativo.

Como se ha indicado en párrafos anteriores, al inicio de la cuarentena y el aislamiento social, se dieron algunas experiencias de realización audiovisual, que partían de la voluntad de realizadoras y realizadores por sumar en un momento crítico. Ahora bien, estas apuestas no eran suficientes, y siendo la ficción propia, el más importante filón de audiencia, América Televisión y Del Barrio Producciones apostaron por realizar su primer proyecto audiovisual en plena pandemia.

Así, el 03 de junio de 2020 se estrenó en América Televisión La Otra Orilla, la primera ficción realizada en pandemia en el Perú. Para este proyecto se fijaron protocolos muy estrictos con pruebas moleculares a todo el equipo artístico y técnico, pocos personajes en escena y demanda de equipos muy pequeños. La Otra Orilla producido y realizado por Del Barrio Producciones, con guión de Rita Solf, contaba la historia de cinco personajes de la primera línea frente a la pandemia: una barrendera -Magda-, un policía -Sergio-, una enfermera -Gloria-, una periodista -Pati-, y un maestro de colegio -Pablo.

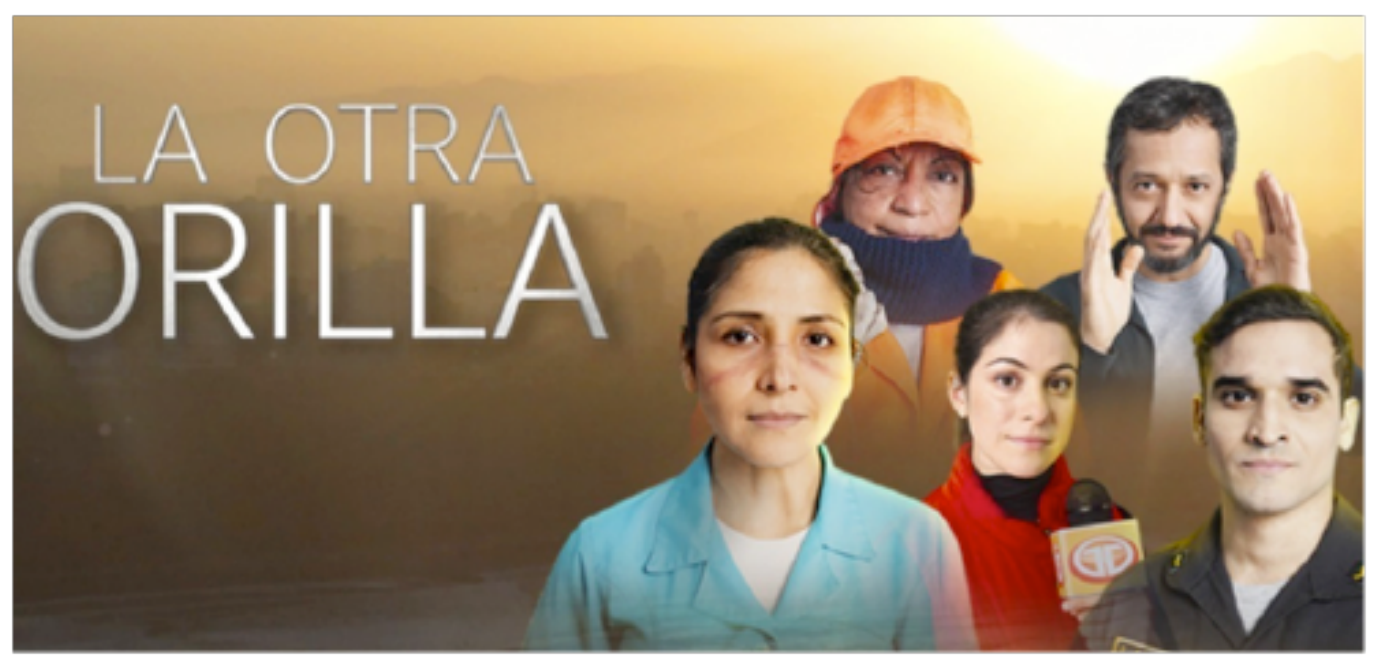

Fuente: América televisión 
La historia se contaba a partir del entrecruzamiento de los personajes en la "nueva normalidad" de la pandemia, y ponía en escena los miedos, los temores, pero también los sueños, las ganas y la resiliencia de una sociedad con fuertes inequidades. Muchas de las escenas tuvieron que ser rodadas en espacios abiertos, con muy pocos personajes y varios equipos técnicos que trabajaban en simultáneo. Algunas de las situaciones se sostenían bastante bien con estas exigencias, otras, no tanto. La línea dramática de Gloria -la enfermera-, por ejemplo, se vio afectada por la exigencia de no tener más de dos personajes en escena, apostando en muchas situaciones por monólogos del personaje, lo que terminó incidiendo en la dramaturgia propia de esa historia.

A pesar de las dificultades para sacar adelante el proyecto, una de las virtudes de La Otra Orilla fue el manejo melodramático de la historia de Pati (periodista) y Sergio (policía), lo que en sí mismo significaba un reto creativo para los directores. Uno de los momentos que generaron mayor sorpresa en la audiencia fue el beso entre ellos, por la exigencia del distanciamiento social.

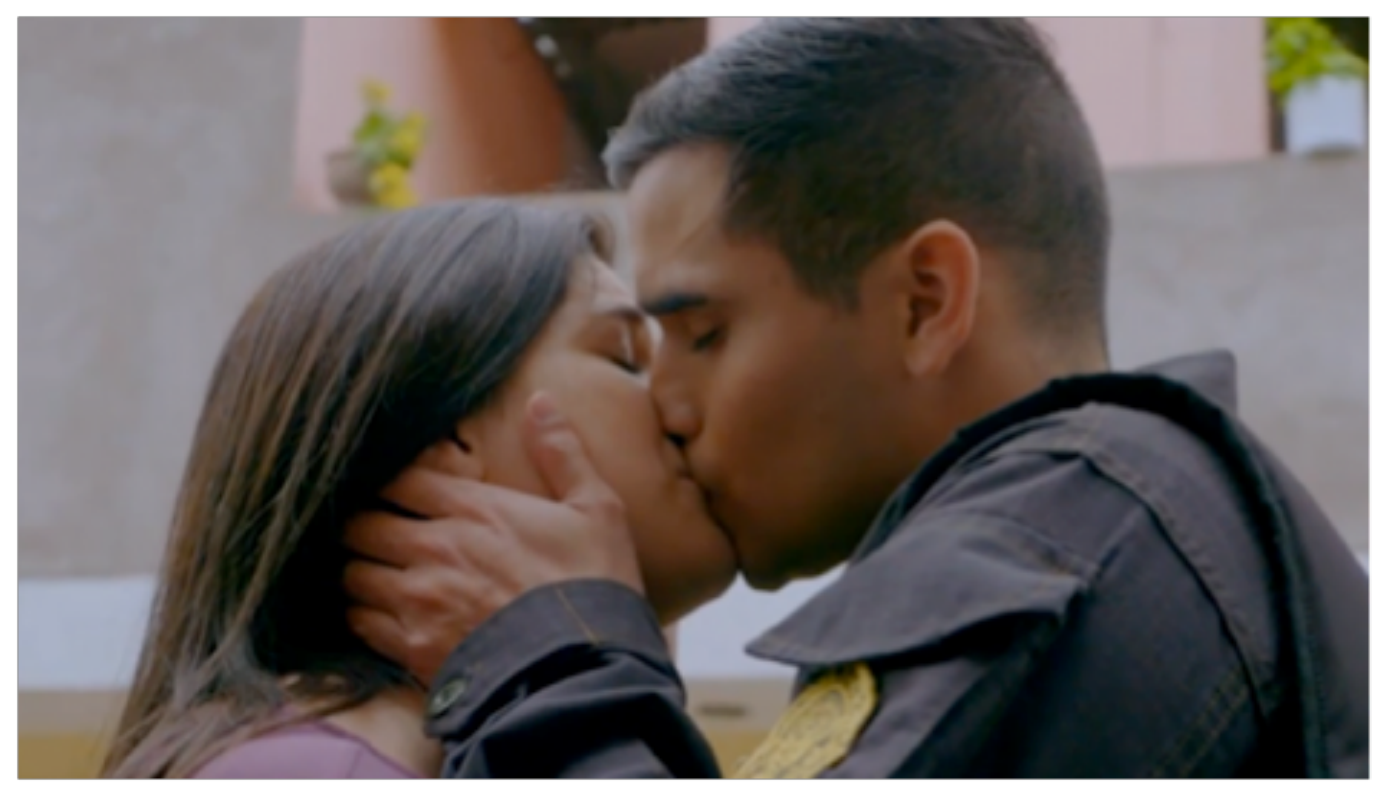

Fuente: Del Barrio Producciones 2020. 
Un momento importante, pues este beso simboliza también el futuro y la esperanza por un retorno a la vida como la conocíamos, en pleno tiempo de distanciamiento social.

La nueva realidad y sus demandas exigió repensar los costos de las producciones, pues estos se incrementaban en el contexto de la pandemia ${ }^{19}$; los tiempos y los contenidos -en muchos casos apostando por productos más cortos, con menos personajes y locaciones. Johanna Lombardi -directora de Ficción para Latinoamérica de Telefónica Media Networks- indicaba en agosto de 2020, que lo más difícil "era la incertidumbre frente al futuro durante el confinamiento" $\square 20$ y precisaba además que el otro gran problema para la realización de ficción es que no había ninguna empresa de seguros que cubriera costos por el COVID-19. En el caso de Telefónica Media Networks, la empresa decidió invertir su tiempo en el desarrollo de los guiones.

El 5 de octubre de 2020 se estrena en horario estelar en América Televisión Mi Vida sin Ti, la segunda telenovela realizada por Del Barrio Producciones en pandemia. Los protocolos de seguridad para esta producción contemplaron -además de los mencionados para el caso de La Otra Orilla- el aislamiento de todo el equipo artístico y técnico en un hotel de la ciudad durante los meses de grabación. El equipo era trasladado cada día desde el hotel a locación y luego de grabadas las diferentes escenas retornaban al hotel. La vida en confinamiento de alrededor de 80 personas posibilitó realizar un producto audiovisual con varias líneas argumentales, más actores en escena, realizar escenas íntimas y el desarrollo dramatúrgico del relato no se vio afectado por los condicionamientos de salud.

La producción audiovisual, especialmente la televisiva, es hoy más que nunca, una industria cultural que dialoga íntimamente con

19 PRODU Webinar Desarrollo y producción de series en pandemia. Realizado el 12 de agosto de 2020. En: https://www.produ.com/webinars/tv/produ-webinar-desarrollo-yproduccion-de-series-en-pandemia 20 Ibídem 
nuestras raíces más profundas, remanso ante la incertidumbre, compañía en el confinamiento y elemento central para experimentar nuestra nueva cotidianeidad. Industria cultural que opera en un escenario complejo de tránsito y convivencia entre la televisión tradicional (broadcast) hacia las segundas o terceras pantallas (streaming), además de las distintas posibilidades digitales que hoy la internet nos ofrece. En ese sentido, cobran sentido las palabras del escritor argentino Federico Mordkowicz cuando nos recuerda "que pueden cambiar los formatos y los soportes, pero la necesidad de contar y consumir historias va a continuar porque está en nuestro ADN" y la pandemia nos lo recordó de manera violenta. 


\section{Referencias}

Cassano, G., Dettleff, J., \& Vásquez, G. (2020). Perú: Lo social y la comedia en la ficción. En I. Vasallo de Lopes \& G. Orozco, Obitel 2020, el melodrama en tiempos de streaming (págs. 253-290). Porto Alegre: Sulina.

Cavieres, E. \& R. Salinas (1991). Amor, sexo y matrimonio en Chile tradicional. Serie Monografías, No 5, Valparaíso, Instituto de Historia, Universidad Católica de Valparaíso.

Convención Belém do Pará. En:

https://www.mimp.gob.pe/files/direcciones/dgcvg/legisinternacional ConvenBelemdoPara.pdf

Lagarde, M. (2008) La violencia contra la mujer tiene que ver "con un problema de los hombres". En: https://www.notimerica.com/sociedad/noticiamexico-marcela-lagarde-dice-violencia-contra-mujer-tiene-ver-problema-hombres-20080416225803.html

Ministerio de la Mujer y Poblaciones Vulnerables (2016). Violencia de género. Marco conceptual para las políticas públicas y la acción del Estado. Lima- Perú. MIMP.

PRODU Webinar Desarrollo y producción de series en pandemia. Realizado el 12 de agosto de 2020. En:https:/www.produ.com/webinars/tv/produ-webinar-desarrollo-y-produccion-de-series-en-pandemia

Segato, R. L. (2016). La guerra contra las mujeres. Madrid, España: Traficantes de Sueños.

Segato, R. L. (2014). Las nuevas formas de la guerra y el cuerpo de las mujeres. Primera edición. Puebla: Pez en el árbol.

Segato, R. L. (2003). Las estructuras elementales de la violencia. Primera edición. Buenos Aires: Universidad Nacional de Quilmes. Prometeo libros. 